\title{
Entry Deterrence in a Duopoly Market
}

\section{Citation}

James D. Dana Jr. and Kathryn E. Spier, Entry Deterrence in a Duopoly Market, 7(1) B. E. J. Econ. Anal. Pol. Article 19 (2007).

\section{Published Version}

doi:10.2202/1935-1682.1653

\section{Permanent link}

http://nrs.harvard.edu/urn-3:HUL.InstRepos:10611782

\section{Terms of Use}

This article was downloaded from Harvard University's DASH repository, and is made available under the terms and conditions applicable to Other Posted Material, as set forth at http:// nrs.harvard.edu/urn-3:HUL.InstRepos:dash.current.terms-of-use\#LAA

\section{Share Your Story}

The Harvard community has made this article openly available.

Please share how this access benefits you. Submit a story.

Accessibility 


\title{
The B.E. Journal of Economic Analysis \& Policy
}

\section{Advances}

\section{Entry Deterrence in a Duopoly Market}

\author{
James D. Dana* Kathryn E. Spier ${ }^{\dagger}$
}

*Kellogg School of Management, Northwestern University, j.dana@neu.edu

${ }^{\dagger}$ Kellogg School of Management and School of Law, Northwestern University and NBER, kspier@law.harvard.edu

\section{Recommended Citation}

James D. Dana Jr. and Kathryn E. Spier (2007) "Entry Deterrence in a Duopoly Market," The B.E. Journal of Economic Analysis \& Policy: Vol. 7: Iss. 1 (Advances), Article 19.

Available at: http://www.bepress.com/bejeap/vol7/iss1/art19

Copyright (c) 2007 The Berkeley Electronic Press. All rights reserved. 


\title{
Entry Deterrence in a Duopoly Market*
}

\author{
James D. Dana Jr. and Kathryn E. Spier
}

\begin{abstract}
In a homogeneous good, Cournot duopoly model, entry may occur even when the potential entrant has no cost advantage and no independent access to distribution. By sinking its costs of production before negotiating with the incumbents, the entrant creates an externality that induces the incumbents to bid more aggressively for the distribution rights to its output. Each incumbent is willing to pay up to the incremental profit earned from the additional output plus the incremental loss avoided by keeping the output away from its rival. This implies that the incumbents are willing to pay up to the market price for each unit of available output. A sequential game in which the incumbents produce first is analyzed, and the conditions under which entry is deterred by incumbents' preemptive capacity expansions are derived.
\end{abstract}

KEYWORDS: Cournot duopoly, entry deterrence

${ }^{*}$ We would like to thank Joseph Harrington, Albert Ma, Michael Whinston, and the anonymous referees, as well as seminar participants at Northwestern University, for their helpful comments. 


\section{Introduction}

The major motion picture studios in the United States, including Disney, Time Warner, and Paramount Pictures, are vertically integrated organizations. In addition to producing expensive Hollywood movies, these companies also own and control distribution channels, cable networks, and television stations. It is not uncommon for small non-integrated film companies to make movies without any financial support from major studios and then later auction them off for hefty sums of money. In January of 2005, for example, Paramount/MTV films purchased the low-budget indie film "Hustle \& Flow" at the Sundance Film Festival. ${ }^{2}$ The bidding war to acquire "Hustle" began during the premier of the film on a Saturday night and culminated on Sunday morning in a final bid of $\$ 16$ million. ${ }^{3}$ According to co-producer Stephanie Allain, "We started ('Hustle') in 2001, taking it to studios, and we couldn't get it done... . Because it is by an independent filmmaker - not because it isn't commercial, which it is." Allain's partner, John Singleton, said, "Every studio and every distributor loved it. ... But they couldn't pull the trigger. We got frustrated and said, 'We're just going to make it.",4

This paper is about the difficulties that entrants face when their competitors are vertically integrated and control access to distribution (or another critical resource). Although entry is certainly difficult when distribution is controlled by incumbents, we show that entry is facilitated when distribution is more competitive. By strategically sinking costs of production or capacity, the entrant can stimulate competition between the vertically integrated incumbents. As in the example of the bidding war for the indie film "Hustle \& Flow" at the Sundance Film Festival, the ability of an entrant to capture rents may be enhanced after its costs have already been sunk. We show that this can be true even when the incumbent firms are forward-looking and can expand their own production levels to preempt entry.

\footnotetext{
1"Hustle" tells the story of an anti-hero, a pimp from Memphis, Tennessee, who is in the midst of a mid-life crisis and is struggling to become a rapper.

${ }^{2}$ The festival, which began in 1978, is one of the most prestigious film festivals in the world and is held annually in Utah. The festival, which showcases the work of independent filmmakers, benefited from the early involvement and support of actor Robert Redford. It also borrows its name from Redford's character in "Butch Cassidy and the Sundance Kid."

${ }^{3}$ This was the largest deal in Sundance history. The deal also included two additional unspecified movies from the same filmmakers. John Beifuss Scripps, "\$16 Million Deal is Sundance Record," Deseret Morning News, January 25, 2005. Other high-priced deals negotiated at Sundance include "The Spitfire Grill" for \$10 million, "Napoleon Dynamite" for \$3 million, and "Little Miss Sunshine" for $\$ 10.5$ million. See also Kate Kelly, "The Sun Rises at Sundance," The Wall Street Journal, January 27, 2005.

${ }^{4}$ Todd McCarthy, "Par Execs 'Hustle' for Hot Pic; Studio Makes \$16 Mil Deal with Singleton," Daily Variety, January 23, 2005.
} 
Specifically, we consider a simple framework in which two vertically integrated Cournot duopolists face the threat of upstream entry. The product is homogeneous; the entrant is no more efficient than the incumbents and does not benefit from product differentiation of any kind. ${ }^{5}$ If the duopolists naively ignore the threat of entry and produce the Cournot duopoly outcomes, the entrant could enter the market and earn positive profits. To see why, suppose that the entrant did in fact sink the cost of producing a small amount of an additional upstream output. Since the entrant's output will be sold by one firm or the other, each firm correctly ignores the impact of the extra output on the price of its inframarginal production (the price will decrease by the same amount regardless of who buys the entrant's output). This implies that the marginal revenue of the entrant's extra output is equal to the market price and that the entrant would produce as if it had access to distribution. ${ }^{6}$ To make the analogy to the Sundance Film Festival example, the movie studios were willing to pay a hefty sum to acquire "Hustle" after it had already been produced ex post, even though they would not have been willing to do so ex ante.

The Cournot duopolists are not naive in our model, however, and they can adjust their own capacity to deter entry. In particular, we show that when the cost of upstream production is sufficiently small, the incumbents will deter entry by symmetrically expanding their output. For an intermediate range of costs, entry is still deterred, but one incumbent produces more than the other. For a high range of costs, entry is accommodated, and the firms' outputs are the same as they would have been if the entrant had independent access to distribution. We also show that these ranges are not mutually exclusive. The intermediate and high ranges overlap, so both entry-deterring and entry-accommodating equilibria exist simultaneously for some parameter values.

It is interesting to note that the incumbents are harmed by their inability to commit not to deal with the entrant. The incumbents compete for the right to distribute the entrant's output, even though the new output will reduce the margin on their existing products. The incumbents would be better off if they could collectively refuse to deal with the entrant or could otherwise restrict the entrant's access to distribution. Furthermore, the incumbents also fail to coordinate their entry deterrence strategies. Interestingly, this leads to over-deterrence. For some parameter values, entry deterrence occurs even though the incumbents' joint profits would have been higher if they had accommodated entry. This happens because the entry-deterring equilibrium is asymmetric, and the larger firm

\footnotetext{
${ }^{5}$ Many of the real-world examples that we use as motivation involve differentiated products. Differentiation is discussed in more detail in the Conclusion.

${ }^{6}$ Molnar (2000) considers a model of horizontal mergers where incentives to merge are shaped by similar negative externalities.
} 
harms its rival as it expands output to deter entry.

We believe that these issues are of broad interest and importance. There are many industries besides the movie industry where distribution is controlled by a small number of vertically integrated firms, and entrants must rely upon one of their rivals to distribute its product. Small drug producers often rely upon large, vertically integrated pharmaceutical companies to market and distribute their products; small airlines (such as Spirit Airlines at O'Hare airport in Chicago) have successfully entered markets where a few dominant firms control access to terminal gates and baggage carousels. ${ }^{7}$ Furthermore, in many of these cases, the incumbent firms have expanded and/or diversified in light of upstream competition. Continental and United Airlines, for example, have expanded their offerings to include point-to-point service to compete with entrants like Southwest. In the last decade, most of the major motion picture studios have developed business units that focus on the production of "specialty" films. Interestingly, specialty film divisions were responsible for most of the best-picture nominees at the Academy Awards in 2005. ${ }^{8}$

Our paper contributes to the game theoretic literature on entry deterrence begun by Spence (1977) and Dixit (1980). They show that by building extra capacity, incumbents can credibly commit to respond aggressively to new entry. Because the cost of capacity is sunk, the threat to lower price if entry occurs is credible. In our paper, incumbents make Spence-Dixit-style capacity commitments even though the entrant cannot sell its output directly to consumers. The incumbents need to make capacity commitments in order to make it credible that neither firm will buy the entrant's capacity.

Gilbert and Vives (1986) and Waldman (1987) extend this literature to consider multiple incumbents. They examine the hypothesis that non-cooperative oligopolists free ride on their rivals' entry deterrence with the result that total entry deterrence is diminished relative to cooperating firms. Gilbert and Vives argue against this hypothesis citing other offsetting effects while Waldman argues that,

\footnotetext{
${ }^{7}$ Ben \& Jerry's, the second-largest producer of superpremium ice cream in the U.S., recently began distributing its ice cream through Pillsbury, maker of the leading superpremium ice cream brand, Hägen-Dazs. Ben and Jerry's announced the switch after a dispute with its former distributor, Dreyer's, a premium-brand ice cream producer who had announced plans to enter the superpremium ice cream market. International markets offer many more examples. U.S. mutual fund providers Citibank and Salomon Smith Barney distribute their products in Japan through vertically integrated competitors. Quaker's Gatorade beverages and Anheuser-Busch's beers are also distributed by rivals in Japan.

${ }^{8}$ These divisions include Disney's Miramax business unit, NBC Universal's Focus Features, Paramount's Paramount Classics, and Time Warner's Warner Independent. Kate Kelly and Merissa Marr, "Time Warner Joins 'Indie' Film Company with HBO, New Line," Wall Street Journal, March 24, 2005.
} 
in the presence of uncertainty, free riding will occur. While our model is quite different and includes no uncertainty, we demonstrate that, under some conditions, our incumbents would be strictly better off if they agreed to accommodate entry.

Rasmusen (1988) extends the Spence-Dixit models by allowing the incumbent to "buy out" the vertically integrated entrant. He shows that the Spence-Dixit result is only valid if the incumbent can commit not to acquire the entrant. In his model the incumbent always finds it profitable to buy the entrant when entry occurs (entry doesn't occur unless a buyout is going to occur). So, the entrant's decision to enter depends not on the entrant's expected profits from producing (though it must be credible for the entrant to stay in the market after sinking its entry costs if it is not acquired) but on how much the incumbent is willing to pay to acquire it. And this in turn depends on how big an impact the entrant has on the incumbent's profits. But Rasmusen's model is fundamentally different from ours because the entrant's outside option is to sell his output himself. Rasmusen argues that entry for buyout is less likely in imperfectly competitive markets because buyout becomes a public good. In contrast, in our model the entrant cannot harm a monopoly incumbent, so buyout is more likely in imperfectly competitive markets.

Our paper is also related to the literature on the persistence of monopoly. Gilbert and Newbery (1982) showed that new capacity is more valuable to an incumbent than it is to a new entrant, so monopolists tend to persist. In our model, duopoly in distribution persists by construction. The entrant's value of capacity is only equal to what it can get by selling it to the incumbents. Nevertheless, we show that for sufficiently low capacity cost the incumbents overproduce to preempt entry in production as well. Krishna (1993) extends Gilbert and Newbery to the case where new capacity becomes available sequentially. Krishna shows that the persistence of monopoly depends on the timing of the arrival of new capacity. In an oligopoly context, Eso, Nocke, and White (2006) show that sequential capacity auctions for exogenously given capacity can explain equilibrium asymmetries in firm size among otherwise identical firms. Other related papers include Kamien and Zang (1990), Reinganum (1983), Lewis (1983), Chen (2000), and Hoppe, Jehiel, and Moldavanu (2006).

Finally, while we do not formally consider the decision of firms to merge vertically, our paper suggests that competition severely limits upstream firms' ability to use downstream foreclosure to limit upstream entry. Hence, it is related to the literature on the anticompetitive effects of vertical mergers (see Salop and Scheffman, 1987, Salinger, 1988, Ordover, Saloner, and Salop, 1990, Hart and Tirole, 1990 and Chen, 2001).

The next section lays out the basic framework for analysis, describes the tim- 
ing of the game, and defines the notation. We then explore several benchmark examples that are useful for understanding our results. The body of the paper characterizes the equilibrium and evaluates its social welfare implications. The final section discusses alternative timings and offers some concluding remarks.

\section{The Model}

There are three firms: A, B, and C. Firms A and B are the incumbents, and Firm $\mathrm{C}$ is the entrant. The entrant differs from the incumbents in two important ways. First, the incumbents, Firms A and B, have access to distribution while Firm C does not. ${ }^{9}$ This implies that Firm $\mathrm{C}$ can only profitably enter if it subsequently sells its output to Firms A or B. Second, Firms A and B make their production (or capacity) decisions before Firm C. Hence, we sometimes refer to Firms A and B as "Stackelberg incumbents".

We assume that production has a constant marginal cost $k>0$ for each firm and that distribution is costless for Firms A and B (and infinitely costly for Firm C). For simplicity we assume the market demand is $p(z)=1-z$, where $z$ is the total amount of output that is distributed to the market by Firms A and B. While our demand assumption is restrictive, it is clear that our results generalize easily to any linear demand function.

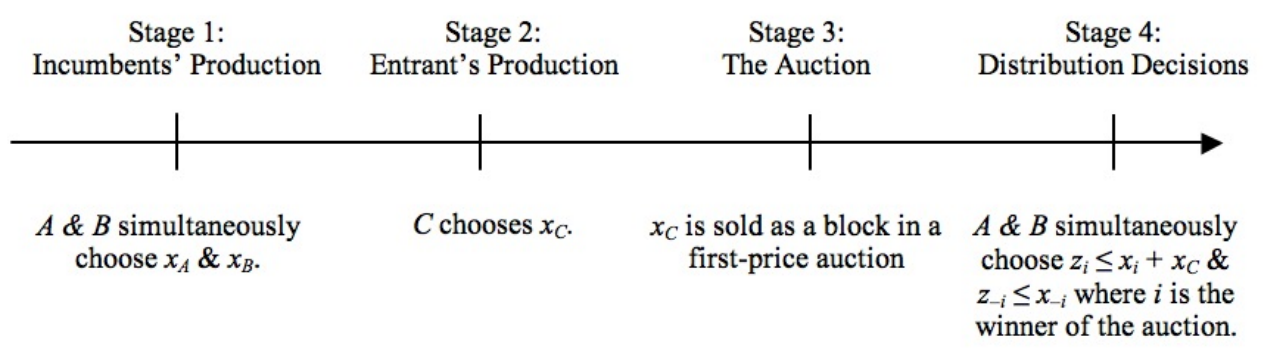

Figure 1: The Timing

The timing of the game is as follows (see also Figure 1). First, in Stage 1, the incumbents, Firms A and B, decide simultaneously and non-cooperatively how

\footnotetext{
${ }^{9}$ This assumption can be motivated in different ways. The simplest motivation is economies of scale in distribution (perhaps spread over multiple products) that blockade the entrant from the distribution market. Another is that the incumbents have brand names that they use to solve a quality-assurance problem with consumers, so the entrant cannot profitably sell to consumers unless it sells the product under an incumbent's brand name. If we assume additionally that the incumbents can only monitor the entrant's quality when they control the distribution of the entrant's product, then the entrant's only option is to distribute through the incumbents.
} 
much to produce, $x_{A}$ and $x_{B}$. In Stage 2, the entrant, Firm $\mathrm{C}$, chooses how much to produce, $x_{C}$. Then, in Stage 3, after all three firms have chosen their outputs, Firm $\mathrm{C}$ sells its output as a block to the incumbent firms.

Assumption 1 The entrant's output is sold to the incumbents, as a block, in a first-price auction.

If Firm $i$ purchases Firm C's output, then the incumbents' interim output endowments are $y_{i}=x_{i}+x_{C}$ and $y_{-i}=x_{-i}$, and if neither firm purchases from the entrant, then $y_{i}=x_{i}, \forall i$. Finally, in Stage 4, each incumbent decides simultaneously and non-cooperatively how much output to distribute to the final market, $z_{i} \leq y_{i}$, and the equilibrium market price is determined.

This is a sequential game of complete information, and we solve for the subgame perfect Nash equilibrium (or equilibria) of the game.

\section{Interpretation}

While this is a static model, it is reasonable to think of the initial production levels, $x_{A}, x_{B}$, and $x_{C}$, as representing one-time capacity decisions and the incumbents' distribution choices, $z_{A}$ and $z_{B}$, as representing the firms' subsequent production decisions subject to capacity constraints. The entrant's sale, $x_{C}$, may involve either a one-time transfer of capacity, i.e., a merger or an acquisition, or the repeated sale of output, i.e., an ongoing contractual relationship to provide distribution and resale. This interpretation of the model is valid as long as the capacity costs are sufficiently large relative to the variable costs of production (which are zero in this interpretation of our model).

In addition, access to distribution can be interpreted as any essential complementary resource. Formally, distribution serves two roles in the paper. First, only a firm with access to distribution can sell to consumers. And second, output can be disposed of freely at the distribution stage. So, any other essential complementary resource, such as a proprietary network or regulatory restrictions, can take the place of distribution as long the free disposal option remains.

\section{Notation}

Here we describe some additional basic notation that will be used throughout the paper. Let $\pi_{i}\left(z_{i}, z_{-i}\right)=z_{i} p\left(z_{i}+z_{-i}\right)$ denote incumbent $i$ 's continuation profit as a function of the final distribution levels. Let $z_{i}^{*}\left(y_{i}, y_{-i}\right)$ denote incumbent $i$ 's equilibrium distribution level as a function of the interim endowments. Let $\Pi_{i}\left(y_{i}, y_{-i}\right)=\pi_{i}\left(z_{i}^{*}\left(y_{i}, y_{-i}\right), z_{-i}^{*}\left(y_{i}, y_{-i}\right)\right)$ denote incumbent $i$ 's continuation profit as a function of the interim endowments. 
Let $R\left(x_{-i}, c\right)$ denote Firm $i$ 's standard Cournot best response as a function of the other firm's output and of Firm $i$ 's own unit $\operatorname{cost} c$ (in our analysis, $c$ will take on the values $k$ and 0 ). In other words,

$$
R\left(x_{-i}, c\right)=\arg \max _{x_{i}} x_{i} p\left(x_{i}+x_{-i}\right)-c x_{i} .
$$

Because we assume that demand is linear, this simplifies to $R\left(x_{-i}, c\right)=\frac{1-x_{-i}-c}{2}$.

We define $x_{0}^{c}$ to be the Cournot duopolist's output when both firms have zero costs, so $x_{0}^{c}$ is defined by

$$
x_{0}^{c}=R\left(x_{0}^{c}, 0\right) \text {. }
$$

With a linear demand function, this reduces to $x_{0}^{c}=\frac{1}{3}$. Similarly, we define $x_{k}^{c}$ to be the Cournot duopolist's output when both firms have costs $k$, so $x_{k}^{c}$ is defined by

$$
x_{k}^{c}=R\left(x_{k}^{c}, k\right),
$$

and because we assume that demand is linear, $x_{k}^{c}=\frac{1-k}{3}$. We define $x_{k, 0}^{s}$ to be the Stackelberg leader's output when the leader has cost $k$ and the follower has zero cost, so

$$
x_{k, 0}^{s}=\arg \max _{x_{A}} x_{A} p\left(x_{A}+R\left(x_{A}, 0\right)\right)-k x_{A},
$$

and because we assume that demand is linear, $x_{k, 0}^{s}=\frac{1}{2}-k$.

Finally, let $r\left(x_{-i}\right)$ denote incumbent $i$ 's best response function with respect to the other incumbent's output when the entrant is expected to subsequently enter and produce as an integrated Stackelberg follower, i.e., $R\left(x_{i}+x_{-i}, k\right)$. So,

$$
r\left(x_{-i}\right)=\arg \max _{x_{i}} x_{i} p\left(x_{i}+x_{-i}+R\left(x_{i}+x_{-i}, k\right)\right)-k x_{i} .
$$

Because we assume that demand is linear, this simplifies to $r\left(x_{-i}\right)=\frac{1-x_{-i}-k}{2}$. Notice that the Stackelberg incumbents produce the same outputs here as they would absent the threat of (vertically integrated) entry.

\section{Benchmarks}

In this section, we consider several benchmark models with alternative market structures. These examples are important for developing intuition for the model and for understanding the scope of our results. The four market structures that we discuss, our three benchmarks models, and our main model are all shown in Figure 2. 
The B.E. Journal of Economic Analysis \& Policy, Vol. 7 [2007], Iss. 1 (Advances), Art. 19

I. One Stackelberg Incumbent and an Entrant With Access to Distribution

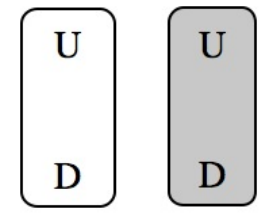

Incumbent Entrant

II. One Stackelberg Incumbent and an Entrant Without Access to Distribution

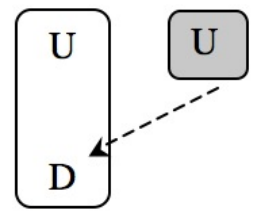

Incumbent Entrant
III. Two Stackelberg Incumbents and an Entrant With Access to Distribution

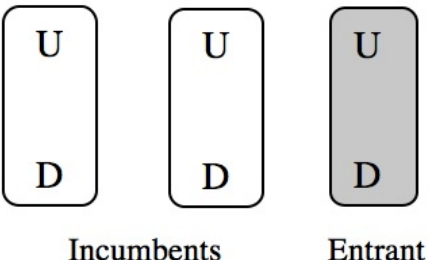

IV. Two Stackelberg Incumbents and an Entrant Without Access to Distribution

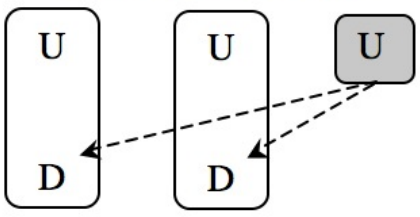

Incumbents Entrant

Figure 2: Alternative Market Structures

\section{Market Structure I: One Incumbent and One Entrant With Access}

This benchmark is simply the well-known Stackelberg Leader/Stackelberg follower case.

Lemma 1 When there is a single incumbent and the entrant has access to distribution, the incumbent produces $\frac{1-k}{2}$, the entrant produces $\frac{1-k}{4}$, and the market price is $\frac{1+3 k}{4}$.

\section{Market Structure II: One Incumbent and One Entrant Without Access}

Another benchmark is a single monopoly incumbent and an entrant that has no access to distribution. In this case, it is easy to see that the single Stackelberg incumbent can extract full monopoly rents by simply producing and distributing the monopoly output itself. When the incumbent produces the monopoly output, the marginal revenue associated with producing and distributing one additional unit is exactly equal the marginal cost, $k$. If the entrant produced any additional output, implying that the total level of production is above the monopoly level, then the incumbent's marginal willingness to pay would be less than $k$ per unit. So, 
regardless of the relative bargaining strengths of the incumbent and the entrant, the entrant cannot expect to receive a price that exceeds his cost of production, and entry is never profitable.

Lemma 2 When there is a single incumbent, and the entrant does not have access to distribution, the incumbent produces $\frac{1-k}{2}$, the entrant produces 0 , and the market price is $\frac{1+k}{2}$.

While it is self-evident that the monopolist will never purchase from the entrant and that the entrant will never produce, we emphasize this result because it contrasts starkly with our results for two incumbents and an entrant without access to distribution (Market Structure IV).

\section{Market Structure III: Two Incumbents and One Entrant With Access}

Our next benchmark is the subgame perfect equilibrium of the game under the assumption that the entrant does have access to distribution.

Lemma 3 When all three firms have access to distribution, the unique equilibrium outputs are $\left\{\frac{1-k}{3}, \frac{1-k}{3}, \frac{1-k}{6}\right\}$, so the total industry output is $x_{A}+x_{B}+x_{C}$ is $\frac{5-5 k}{6}$, and the associated market price is $p=\frac{1+5 k}{6}$.

\section{Proof: See Appendix.}

Note that when Firm $\mathrm{C}$ has access to distribution, the equilibrium is still asymmetric because Firms A and B are able to choose their capacities first. Later, we will see that this equilibrium may also be the unique equilibrium of the game even when Firm $\mathrm{C}$ does not have access to distribution.

\section{Market Structure IV: Two Incumbents and One Entrant Without Access}

Market Structure IV is the case analyzed in the remainder of the paper. Before characterizing the equilibria of this game, it is useful to illustrate why the outcome of this game differs dramatically from the unique equilibrium outcome in Market Structure II.

Suppose that the entrant has no independent access to distribution and that the incumbents each produce $x_{k}^{c}=\frac{1-k}{3}$, their Cournot outputs. In other words, suppose that, as in Market Structure II, the incumbents do not expect the entrant to produce because it has no access to distribution. In this case, the market price is $\frac{1+2 k}{3}$, which is strictly greater than $k$. As long as the entrant does not enter, the incumbents earn positive profit margins producing and selling their Cournot outputs. 
Lemma 4 Suppose there exist two incumbents and one entrant who has no access to distribution. If the incumbents each naïvely produce the Cournot duopoly output, then the entrant will produce the same output as in Market Structure III and will distribute through the incumbent firms.

To see this, suppose that the entrant, lacking direct access to distribution, produces a small amount $\Delta$ and attempts to auction this output to the two incumbents. If Firm A wins the auction then Firm A will distribute the additional output, and the market price will fall (ever so slightly) below $\frac{1+2 k}{3}$. If Firm B wins the auction, Firm B will distribute the additional output as well, and the market price will fall to the same level. Since the market price for the additional output is slightly below $\frac{1+2 k}{3}$ regardless of who wins, each incumbent is willing to pay slightly below $\frac{1+2 k}{3}$ per unit for the entrant's output.

The negative externality in the auction between the two incumbents allows the entrant to extract the full market price for its additional output. So, the entrant's output is sold at the market price to the incumbents, and the entrant's profits are the same as if it sold directly to consumers. And this is true regardless of how much the entrant produces as long as the implied market price is greater than $k$.

Interestingly, the incumbents would be better off if they could collectively refuse to deal with the entrant. First, the entrant has forced them to sell beyond their Cournot duopoly output. Second, the entrant has induced them to pay a premium for this output, since the price paid in the auction is above the marginal cost of $k$. If the two incumbents could jointly commit not to participate in the auction, then the entrant would have no outlet for its output, and the two incumbents would be jointly better off. In fact, both incumbents would be better off if even just one of them made an ex ante unilateral commitment not to buy the entrant's output.

In the rest of the paper, we explore how the incumbents can, in effect, commit not to trade with the entrant by increasing their Stage 1 production, and we ask under what circumstances the incumbents will accommodate entry and under what circumstances they will produce enough to deter entry.

\section{Stage 4: The Distribution Decisions}

Suppose that Firms A and B have output endowments of $y_{A}$ and $y_{B}$ at the beginning of the Stage 4 distribution subgame. How much of these endowments will they sell, or distribute, to the final market?

Firm A and, by analogy, Firm B will choose their distribution to maximize their continuation profits, $z_{A} p\left(z_{A}+z_{B}\right)$, subject to $z_{A} \leq y_{A}$. So, it follows that 
$z_{A}=\min \left\{R\left(z_{B}, 0\right), y_{A}\right\}$ where $R$ is the Cournot duopoly best-response function with zero costs defined above, and more generally:

Lemma 5 Given interim endowments $y_{A}$ and $y_{B}$, Firms $A$ and $B$ 's distribution levels, $z_{A}^{*}\left(y_{A}, y_{B}\right)$ and $z_{B}^{*}\left(y_{A}, y_{B}\right)$, uniquely solve $z_{A}=\min \left\{R\left(z_{B}, 0\right), y_{A}\right\}$ and $z_{B}=$ $\min \left\{R\left(z_{A}, 0\right), y_{B}\right\}$.

Figure 3 depicts each of the equilibrium distribution levels, $z_{A}^{*}\left(y_{A}, y_{B}\right)$ and $z_{B}^{*}\left(y_{A}, y_{B}\right)$, as functions of the firms' interim output endowments, $y_{A}$ and $y_{B}$. The dashed lines represent the production best-response curves, $R\left(x_{-i}, k\right)$. The solid lines represent the distribution best-response curves, $R\left(x_{-i}, 0\right)$.

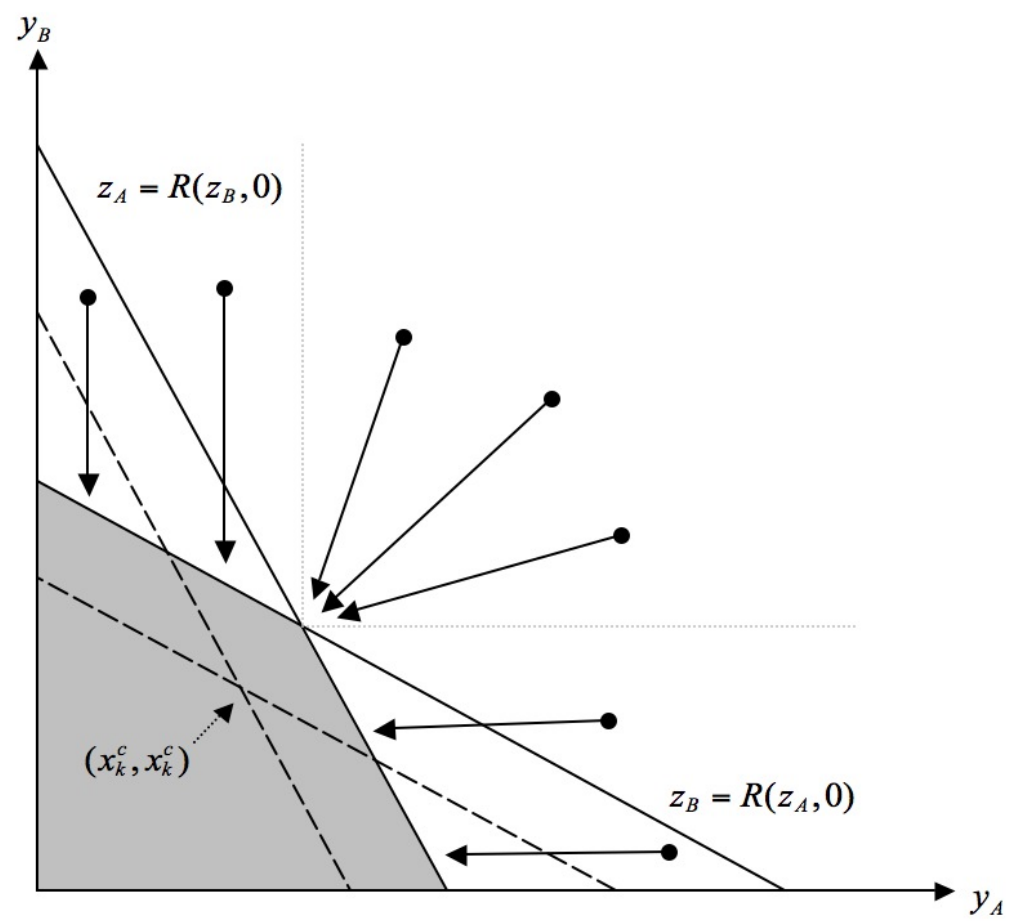

Figure 3: The Distribution Decisions

Within the shaded area of Figure $3, z_{A}^{*}=y_{A}$ and $z_{B}^{*}=y_{B}$. In other words, both incumbents would distribute and sell additional output if they had it. This is particularly important for our purposes. Intuitively, both firms' interim endowments satisfy $y_{i} \leq R\left(y_{-i}, 0\right) \forall i$, so the marginal revenue from selling a unit of output is strictly positive for both firms regardless of what the other firm distributes. So, in the shaded area the incumbents will distribute all of their output. Whenever both incumbents prefer to distribute additional output, as opposed to withholding 
it from the market, the entrant will be able to sell its output to incumbents at the market clearing price.

When one or both of the firms' interim endowments are greater than their distribution best responses, that is, $y_{i}>R\left(y_{-i}, 0\right)$ for some $i$ (so we are outside the shaded region), then at least one firm will withhold some output from the market. Moreover, the firm with more output will always withhold more. Intuitively, the larger firm has more to gain from withholding some of the production from the market because it benefits more from an increase in the market price.

This is easy to see when only one firm's interim endowment is greater than its distribution best response. When only Firm A's interim endowment is greater than its distribution (or zero-cost) best-response, then in the distribution stage Firm B has an incentive to distribute all its output regardless of Firm A's distribution, and only Firm A will withhold output from the market: $z_{A}=R\left(y_{B}, 0\right)$ and $z_{B}=y_{B}$. Similarly, if only Firm B's interim endowment is greater than its distribution best response, then in the distribution stage Firm A has an incentive to distribute all its output regardless of Firm B's distribution, and only Firm B will withhold output from the market: $z_{B}=R\left(y_{A}, 0\right)$ and $z_{A}=y_{A}$.

When both of the firms' interim endowments are greater than their distribution best responses, $y_{i}>R\left(y_{-i}, 0\right), \forall i$, then which firm withholds output from the market depends on whether or not $y_{i}>x_{0}^{c}$. Intuitively, the larger firm has more incentive to withhold output, so it reduces its output until either it is no longer the larger firm, or the distribution levels reach the boundary of the shaded region.

The fact that the larger firm has a weakly greater incentive to withhold output is important for understanding the auction that we consider in Stage 3.

\section{Stage 3: The Auction}

This section analyzes the outcome of the auction at Stage 3. Since this is a game of complete information, a first-price auction clearly implies that the incumbent who values the entrant's output more acquires the output and that the price paid is equal to the valuation of the other incumbent. ${ }^{10}$ But which firm will acquire the entrant's output, and for how much? Recall that $\Pi_{i}\left(y_{i}, y_{-i}\right)$ denoted Firm i's continuation profit as a function of the interim endowments. Therefore, in the auction, Firm A's valuation (or the most the firm is willing to pay for the block of output) is $\Pi_{A}\left(x_{A}+x_{C}, x_{B}\right)-\Pi_{A}\left(x_{A}, x_{B}+x_{C}\right)$, and Firm B's valuation is

\footnotetext{
${ }^{10}$ This is the unique outcome of a first-price auction and an equilibrium outcome of a secondprice auction. However, it is also the equilibrium outcome of a variety of multi-player bargaining games.
} 
$\Pi_{B}\left(x_{A}, x_{B}+x_{C}\right)-\Pi_{B}\left(x_{A}+x_{C}, x_{B}\right)$, and the price paid to the entrant is the minimum of these two valuations.

Intuitively, if both firms would distribute all of the entrant's output conditional on winning the auction, then both firms' valuations are equal to $x_{C} p\left(x_{A}+x_{B}+x_{C}\right)$ and thus the same. So, if $\left(x_{A}, x_{B}\right)$ lies in the interior of the shaded region in Figure 3 , then both incumbents value the entrant's output at the market price. If the entrant produces a small amount, it can sell its output to the incumbents at the market price.

However, if either firm has an incentive to withhold any of the entrant's output from the market, then the firm that produces more output initially internalizes more of the gains from withholding output and therefore withholds more output conditional on winning the auction. In other words, the larger firm values the entrant's output more than the smaller firm. This implies the following:

Lemma 6 Without loss of generality, let $x_{A} \geq x_{B}$. Then Firm $A$ values the entrant's output, $x_{C}$, at least as much as Firm B, that is,

$$
\Pi_{A}\left(x_{A}+x_{C}, x_{B}\right)-\Pi_{A}\left(x_{A}, x_{B}+x_{C}\right) \geq \Pi_{B}\left(x_{A}, x_{B}+x_{C}\right)-\Pi_{B}\left(x_{A}+x_{C}, x_{B}\right) .
$$

When this inequality is strict, Firm A wins the auction. ${ }^{11}$ Otherwise, equilibria exist in which either firm wins the auction. But in either case, the equilibrium price paid for Firm C's output is Firm B's valuation, or $\Pi_{B}\left(x_{A}, x_{B}+x_{C}\right)-$ $\left.\Pi_{B}\left(x_{A}+x_{C}, x_{B}\right)\right\}$.

\section{Proof: See Appendix.}

The following assumption simplifies the proofs and the exposition but is not required for the results:

Assumption 2 When the firms' valuations are the same and the auction has multiple equilibria, we select the equilibrium in which the larger incumbent wins the auction.

Lemmas 5 and 6 imply that, as long as $x_{B}+x_{C}<x_{0}^{c}$, Firm B's valuation (and hence the entrant's revenue) will be $x_{C} p\left(x_{A}+x_{B}+x_{C}\right)$. So, unless each incumbents' output is sufficiently large to begin with, the entrant will be able to produce and sell at the market price.

The intuition for almost all of our results can easily be seen at this point. As described earlier, if the incumbents produce in the interior of the shaded region

\footnotetext{
${ }^{11}$ Since the larger firm always values additional output more than the smaller firm, the assumption that the entrant's output is sold as a block does not seem particularly restrictive.
} 
in Figure 3, the entrant will be able to enter and sell its output at the market price. It is as if the entrant had access to distribution. So, a candidate equilibrium in the interior of the shaded region is an equilibrium in which entry is accommodated, and the outputs are the same as the equilibrium outputs in Market Structure III in which the entrant has access to distribution, $\left\{\frac{1-k}{3}, \frac{1-k}{3}, \frac{1-k}{6}\right\}$. The incumbents accommodate entry but have a first-mover advantage.

Alternatively, the incumbents might produce at the boundary of the shaded region and deter entry. Indeed, given any candidate equilibrium in the shaded region of Figure 3, each firm could unilaterally move to the boundary. When the costs of capacity $k$ are very low, it shouldn't be surprising that all of the equilibria will be at the boundary. But when the costs are very high, the only equilibrium is the entry-accommodating equilibrium; the entrant produces its best response to the incumbents' output and distributes its output through one of the incumbents.

Characterizing the equilibria is, in fact, more subtle than the simple intuition above suggests. Most importantly, the entrant will only enter if the market price is greater than $k$, so being in the interior shaded region is not sufficient for entry to take place. Second, if the incumbents' interim endowments are sufficiently asymmetric, entry will take place even if the endowment point lies on, or outside, the boundary of the shaded area. These two issues complicate the analysis and, as a consequence, hide some of the intuition of the paper. They are also the main reason we were unable to generalize the model beyond linear demand. In the next section of the paper, we carefully analyze the entrant's production decision. ${ }^{12}$

\section{Stage 2: The Entrant's Production Decision}

When $x_{A} \geq x_{B}$, the entrant's revenue is $\left.\Pi_{B}\left(x_{A}, x_{B}+x_{C}\right)-\Pi_{B}\left(x_{A}+x_{C}, x_{B}\right)\right\}$, the profit that Firm B earns when it acquires the entrant's output less the profit it earns when Firm A acquires the entrant's output. Clearly, entry will take place if and only if $\left.\Pi_{B}\left(x_{A}, x_{B}+x_{C}\right)-\Pi_{B}\left(x_{A}+x_{C}, x_{B}\right)\right\}-k x_{C}>0$ for some $x_{C}>0$. The following lemma characterizes the conditions under which entry will take place:

Lemma 7 Entry will occur if and only if $\left(x_{A}, x_{B}\right)$ satisfies one of the following conditions:

1. $x_{A}<R\left(x_{B}, 0\right), x_{B}<R\left(x_{A}, 0\right)$, and $p\left(x_{A}+x_{B}\right)>k($ Region $A)$;

2. $x_{A} \geq R\left(x_{B}, 0\right)$ and $x_{B}<\min \left\{x_{k, 0}^{s}, x_{0}^{c}\right\} \leq R\left(x_{A}, 0\right)$ (Region $\left.D_{1}\right)$;

\footnotetext{
${ }^{12}$ The final step will be to characterize which points on the boundary of the shaded region are equilibria of the first-stage game. This is done in Section 7 of the paper.
} 
3. $x_{B} \geq R\left(x_{A}, 0\right)$ and $x_{A}<\min \left\{x_{k, 0}^{s}, x_{0}^{c}\right\} \leq R\left(x_{B}, 0\right)$ (Region $\left.D_{2}\right)$.

Proof: See the more general statement of this result (Lemma 8) and its proof in the Appendix.

Lemma 7 is described in Figures 4, 5, and 6.

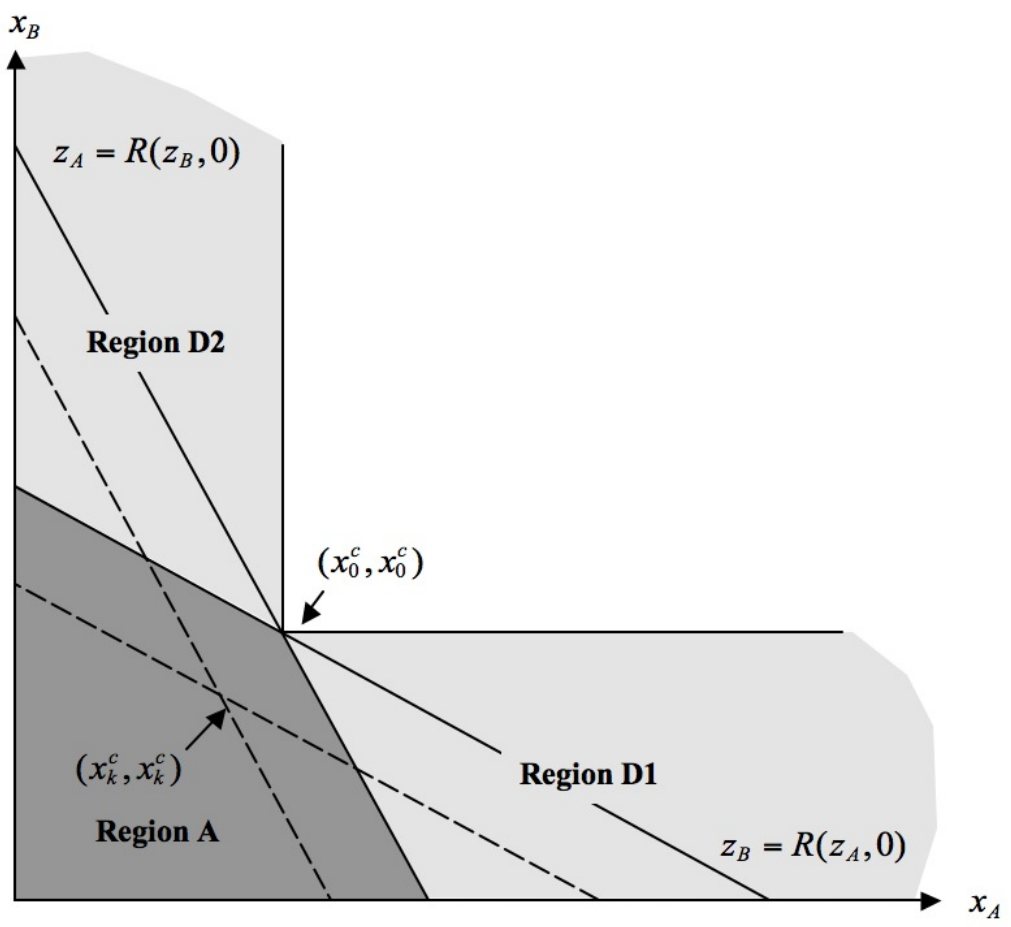

Figure 4: Regions in Which Entry Occurs: $x_{k, 0}^{s}>x_{0}^{c}$, or $k \leq \frac{1}{6}$

The three figures differ in the level of costs, $k$. Recall that in Figure 3, the shaded area depicted the region in which both incumbents placed value on incremental output, and as a consequence Firm $\mathrm{C}$ could enter and sell its output to the incumbents at the market price. The shaded area in Figures 4, 5, and 6 depicts the same region except that we impose the additional restriction that $p>k$, implying that some degree of entry is profitable. Figure 4 depicts the case in which costs are in the lowest range (that is, low enough to imply $x_{k, 0}^{s} \geq x_{0}^{c}$ ). Figure 5 depicts the case in which costs are in an intermediate range (the costs are high enough that $x_{k, 0}^{s}<x_{0}^{c}$ but still low enough to imply $\left.p\left(x_{0}^{c}+x_{0}^{c}\right)>k\right)$. Figure 6 depicts the case where costs are in the highest range (in particular, $p\left(2 x_{0}^{c}\right)<k$ so the profitability constraint binds in condition 1 of the lemma). 


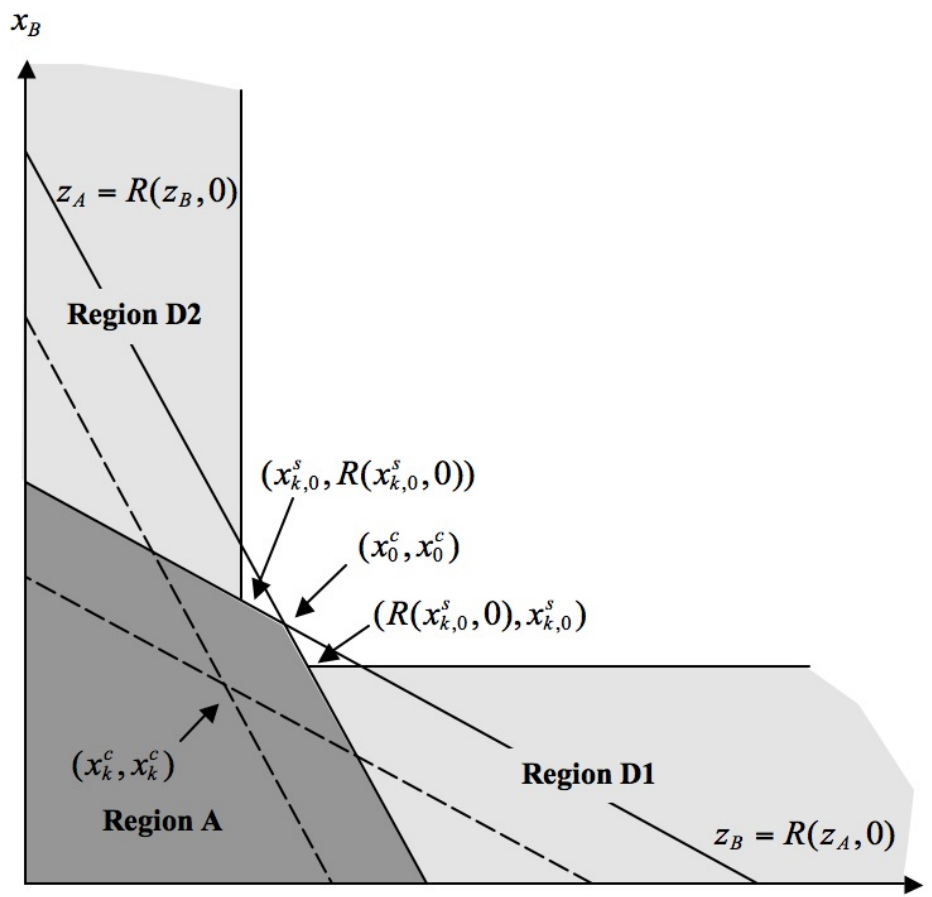

Figure 5: Regions in Which Entry Occurs: $x_{k, 0}^{s}<x_{0}^{c}$ and $p\left(x_{0}^{c}+x_{0}^{c}\right)>k$, or $k \in\left(\frac{1}{6}, \frac{1}{3}\right)$

Lemma 7 states that if the incumbents' production levels, $x_{A}$ and $x_{B}$, are both greater than or equal to $x_{0}^{c}$, then Firm $\mathrm{C}$ cannot profitably enter. This is quite intuitive. By Lemma 5, neither firm would distribute any of the entrant's output if they acquired it, so neither firm would be willing to pay anything for it. Neither firm receives any direct value from the additional output and, just as important, there is no value in keeping the output away from the rival incumbent. It follows that if $x_{A} \geq x_{0}^{c}$ and $x_{B} \geq x_{0}^{c}$ then Firm $\mathrm{C}$ will not produce.

At the other extreme, if the incumbent's production levels, $x_{A}$ and $x_{B}$, lie inside the distribution best-response functions, then the entrant may find entry profitable. In this region, both firms would distribute additional output if they had it, so if Firm C produces a small amount, it can sell its output at the market price. However, entry is only profitable if $p>k$. It follows that Firm C will enter if $x_{A}<R\left(x_{B}, 0\right), x_{B}<R\left(x_{A}, 0\right)$, and $p\left(x_{A}+x_{B}\right)>k$, that is, if $x_{A}$ and $x_{B}$ satisfy condition 1 in Lemma 7 and are in Region A of Figures 4, 5, and 6. The third constraint binds only when $k$ is large, as shown in Figure 6. 
Dana and Spier: Entry Deterrence in a Duopoly Market

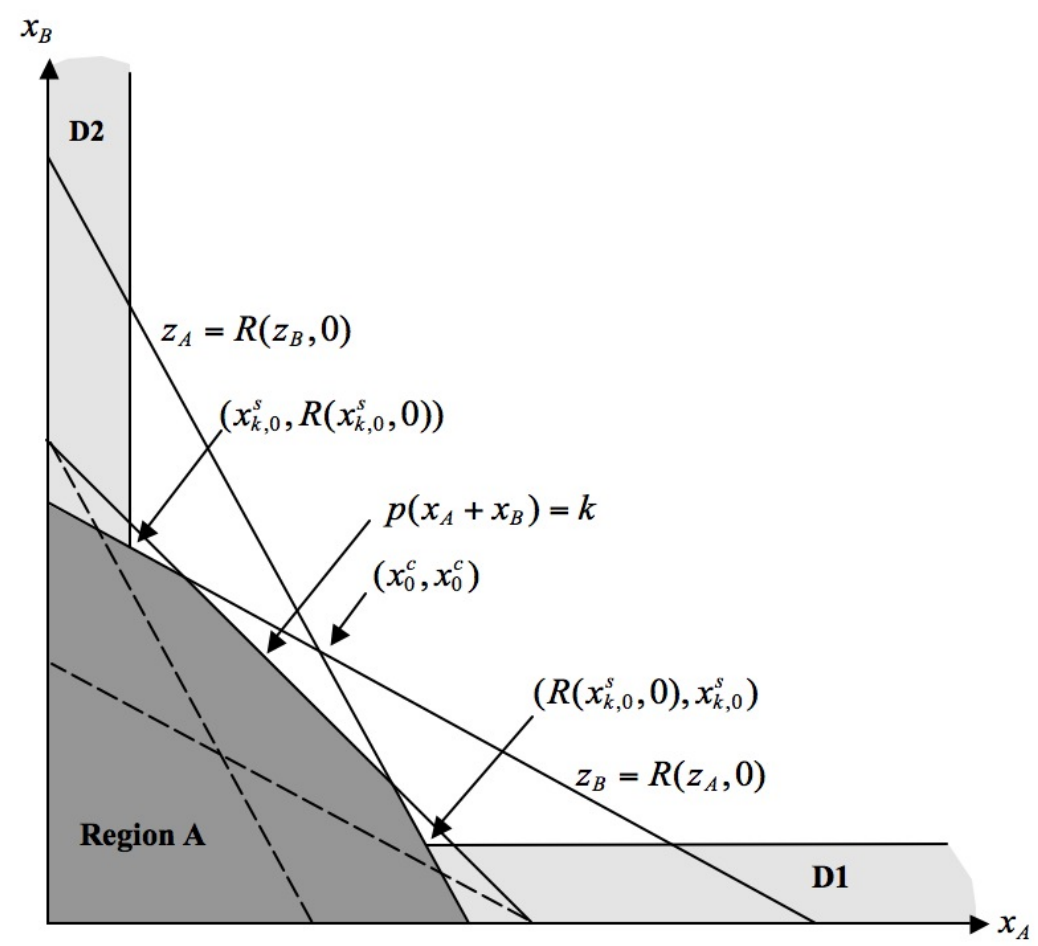

Figure 6: Regions in Which Entry Occurs: $x_{k, 0}^{s}<x_{0}^{c}$ and $p\left(x_{0}^{c}+x_{0}^{c}\right)<k$, or $k \geq \frac{1}{3}$

In Region D1 of the figures, the larger firm (Firm A) acts like a zero-cost Cournot competitor. In the distribution subgame, the larger firm distributes its zero-cost best response to the (expected) distribution level of the smaller firm (Firm B). In other words, the larger of the two firms is a zero-cost Stackelberg follower. In the absence of entry, the smaller firm's optimal output would be $x_{k, 0}^{s}$. If it were to produce less than this amount, then its marginal valuation for the entrant's output would be greater than $k$, deeming entry profitable. If the smaller firm were to produce more than $x_{0}^{c}$, then its maximal willingness to pay would be less than $k$, and entry would be unprofitable. A similar reasoning applies to Region D2 of the figures. These regions are also discussed in more detail in the Appendix in the proof of Lemma 8.

\section{Stage 1: Incumbents' Production Decisions}

We begin by considering the case in which the cost of capacity, $k$, is large. Specifically, we suppose that costs are larger than $1 /(2 \sqrt{2})$. In this case, entry is ac- 
commodated. Despite anticipating entry, Firms A and B would rather buy all of the entrant's output than produce enough output to deter entry.

Proposition 1 A pure-strategy, entry-accommodating, subgame-perfect Nash equilibrium of the form $\{\bar{x}, \bar{x}, R(\bar{x}+\bar{x}, k)\}$, where $\bar{x}=r(\bar{x})$, exists if and only if $k \geq .261$. Under our assumption that demand is linear, the equilibrium production is $\left\{x_{A}, x_{B}, x_{C}\right\}=\left\{\frac{1-k}{3}, \frac{1-k}{3}, \frac{1-k}{6}\right\}$, and the market price is $\frac{1+5 k}{6}$. No other pure-strategy equilibrium exists in which entry is accommodated.

Proof: See Appendix.

Proposition 1 shows that when production costs are sufficiently large, an equilibrium exists in which entry is accommodated. Moreover, if it exists, the entryaccommodating equilibrium has the same output as the equilibrium output in Market Structure III, in which the entrant has access to distribution, even though the entrant must distribute its output through one of the incumbents. The incumbents accommodate entry, but as Stackelberg leaders they produce more than the entrant.

We next consider the case in which the cost of capacity is very small. When the marginal cost of production is less than $1 / 6$, there is a symmetric, subgameperfect Nash equilibrium in which entry is deterred. Each incumbent produces $x_{0}^{c}$. Since neither incumbent values additional output, the negative externality is eliminated. So, neither firm is willing to pay for Firm C's output, and C will not produce.

Proposition 2 A symmetric, pure-strategy, subgame-perfect Nash equilibrium of the form $\left\{x_{0}^{c}, x_{0}^{c}, 0\right\}$ where $x_{0}^{c}=R\left(x_{0}^{c}, 0\right)$ exists if and only if $k \leq \frac{1}{6}$. Given linear demand, $x_{0}^{c}=\frac{1}{3}$, and the equilibrium production is $\left\{\frac{1}{3}, \frac{1}{3}, 0\right\}$. The incumbents sell all that they produce, and entry is deterred.

Proof: See Appendix.

Figure 4 depicts the entrant's decision when $k \leq \frac{1}{6}$. When costs are low, the only point on the boundary of the shaded area at which entry is deterred is $\left\{x_{0}^{c}, x_{0}^{c}, 0\right\}$. And not surprisingly, this is the unique pure-strategy equilibrium.

When the cost is slightly larger than $1 / 6$, then if each firm thought the other was producing $x_{0}^{c}$, they would each have a unilateral incentive to produce less than $x_{0}^{c}$. Although this deviation induces entry, the deviator is strictly better off. This is because $x_{k, 0}^{s}<x_{0}^{c}$, and each firm realizes if they lower their output by $\varepsilon$, entry will occur, their rival will win the auction and distribute $R\left(x_{0}^{c}-\varepsilon, 0\right)$. Since 
their rival is acting as a follower, it is in their interest to shift their output toward the Stackelberg leader output. While there is no symmetric equilibrium in which entry is deterred, entry can still be deterred in a non-cooperative equilibrium when the strategies of Firms A and B are asymmetric.

Proposition 3 Asymmetric, pure-strategy, subgame-perfect Nash equilibria of the form $\left\{x_{k, 0}^{s}, R\left(x_{k, 0}^{s}, 0\right), 0\right\}$, or analogously, $\left\{R\left(x_{k, 0}^{s}, 0\right), x_{k, 0}^{s}, 0\right\}$ exist if and only if $k \in\left(\frac{1}{6}, \frac{1}{2 \sqrt{2}}\right)$. With linear demand, the equilibria are $\left\{\frac{1-2 k}{2}, \frac{1+2 k}{4}, 0\right\}$ and $\left\{\frac{1+2 k}{4}, \frac{1-2 k}{2}, 0\right\}$.

\section{Proof: See Appendix.}

In the first of the two equilibria in Proposition 3, Firm A produces the Stackelberg leader output and Firm B produces its best response, yet Firm A is the smaller firm! This paradoxical result occurs because Firm A's costs are $k$ (cost are relatively large in this case) while Firm B acts as if its costs were zero. Firm $\mathrm{C}$ produces zero, and Firms $\mathrm{A}$ and $\mathrm{B}$ 's equilibrium sales are equal to their production. Firm B deters entry and allows Firm A to free ride. ${ }^{13}$ However, in this equilibrium, Firm B produces more than Firm A, so it earns strictly greater profits. Each firm prefers the equilibrium in which it is the Stackelberg follower. Note also that because Firm B produces more, it internalizes more of the benefits of entry deterrence.

Figure 5 characterizes the entrant's decision for all $x_{A}$ and $x_{B}$ when $k \in\left(\frac{1}{6}, \frac{1}{3}\right)$, which includes the region in which Proposition 3 holds and the asymmetric equilibrium exists.

Proposition 4 proves that Propositions 1 through 3 characterize all of the purestrategy, subgame-perfect Nash equilibria of the game.

Proposition 4 The equilibrium described in Proposition 2 and the two equilibria described in Proposition 3 are the unique entry-deterring equilibria of the game.

\section{Proof: See Appendix.}

This is easy to see intuitively. Suppose another equilibrium existed of the form $\{x, R(x, 0)\}$. First, note that this could only be an equilibrium if $x<R(x, 0)$. In the proof, we show that if the smaller firm produces $s=x \pm \varepsilon$, the rival will distribute $R(s, 0)$. Intuitively, if the smaller firm increases its output, the rival will dispose of some of its output. And, if the smaller firm decreases its output, the

\footnotetext{
${ }^{13}$ Gilbert and Vives (1986) examine free riding in a multiple-incumbent entry deterrence model in which the entrant has access to distribution.
} 
entrant will enter, the rival will win the auction and distribute $R(s, 0)$. So, if the equilibrium is asymmetric, the smaller firm must be producing $x_{k, 0}^{s}$.

Propositions 1 though 4 are summarized in Figure 7. In particular, Figure 7 emphasizes that there exists a range of capacity costs for which the asymmetric entry-deterring equilibrium (Proposition 3) and the entry-accommodating equilibrium (Proposition 1) both exist.

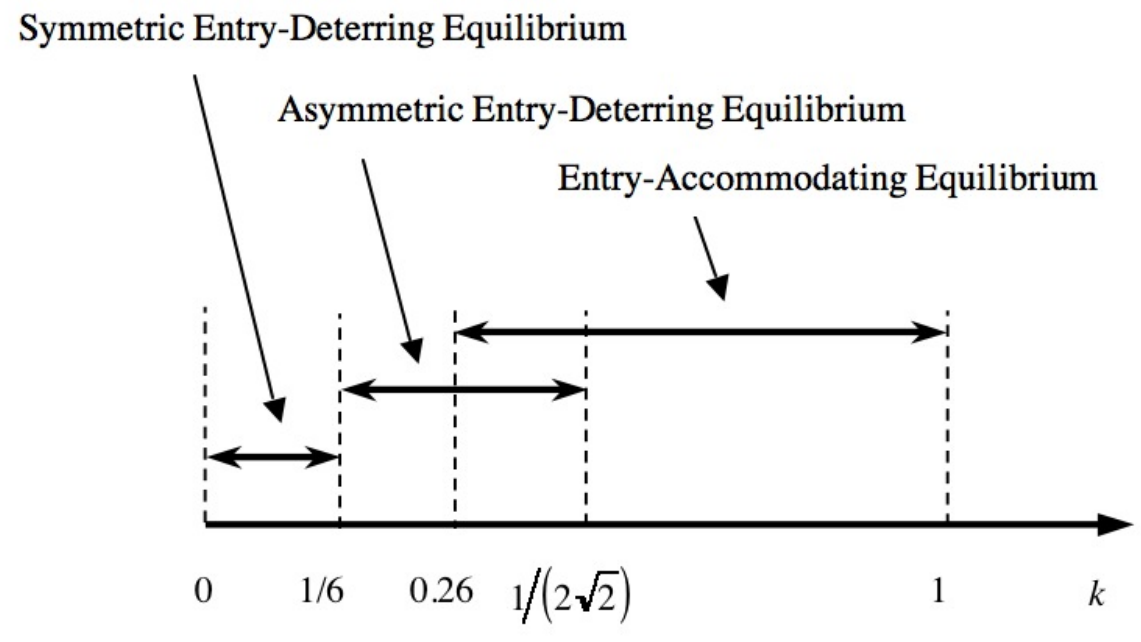

Figure 7: Subgame-Perfect Equilibria as a Function of $k$

Finally, it is straightforward to analyze social welfare. For all $k$ greater than $1 / 4$, the output in the asymmetric entry-deterring equilibrium, $x_{k, 0}^{s}+R\left(x_{k, 0}^{s}, 0\right)=$ $1 / 2-k+(1 / 2+k) / 2=(3-2 k) / 4$, is greater than the output in the entryaccommodating equilibrium, $(5-5 k) / 6$. This means that in the range of $k$ in which the asymmetric entry-deterring equilibrium and the entry-accommodating equilibrium both exist, i.e., $k \in[.261204,1 /(2 \sqrt{2})]$, welfare is higher when entry is deterred. Requiring the incumbents to distribute the entrant's output would lower welfare. Nevertheless, for $k$ less than $1 / 4$, entry deterrence reduces welfare (relative to a requirement that $\mathrm{A}$ and $\mathrm{B}$ distribute the entrant's output).

\section{Conclusion}

This paper has considered the plight of an entrant who faces two significant challenges. First, the incumbent firms are vertically integrated and control the distribution channels. Second, the entrant has no obvious source of competitive advantage; its costs are no lower than the incumbent firms', and its product is no 
better. Nevertheless, the entrant may be able to extract rents from the incumbents. After sinking irreversible investments, the entrant can take advantage of a negative externality that exists between the incumbents. An incumbent's willingness to pay for the entrant's output or capacity is higher when it believes that the other incumbent is willing to acquire and distribute the entrant's output, too. We have showed that when the costs of production are low, the incumbents will expand their production in anticipation of the auction and deter entry altogether. When the costs of production are high, however, we showed that the entrant will gain full access to the market and behave like a vertically integrated producer.

Our results are relevant to public policy debates. First, our results imply that incumbents can generate significant profit increases through agreements not to deal with entrants. Such agreements are already per se illegal. In the telecommunications industry, incumbents have historically been required to provide universal access to rival firms. Our results suggest that access requirements could increase welfare when costs are small, but decrease welfare when costs are large. This is because access requirements would cause the incumbents to stop engaging in entry deterrence, which is socially preferred to entry.

Note, however, that we have assumed that the firms' costs were symmetric. We conjecture that even if the entrant had higher costs of production, when $k$ is sufficiently large the incumbents accommodate entry. This is important because it suggests a potential efficiency defense for such agreements not to deal with entrants.

In order to derive concrete results, we have made a number of simplifying assumptions. First, we have assumed a single entrant. If there were more than one entrant, then the incumbents would probably invest more in entry deterrence. (The cost of entry is higher when the entrants produce more.) It is likely that the range of costs for which entry-accommodating equilibria exist would shrink and that the range of costs for which asymmetric entry-deterring equilibria exist would grow. (The range of costs for which the symmetric entry-deterring equilibria exists stays the same.) Second, we assumed that the distribution costs were zero. If the incumbents had positive marginal costs of distribution it would be much easier to deter entry. More generally as the proportion of costs that are sunk in the production stage decreases, the importance of the entrant's commitment declines. Third, we restricted attention to linear demand functions. This assumption was made in order to calculate the profit changes resulting from a large deviations in output. This was particularly useful because our model has discontinuous best response functions. Although we believe that many of the insights and intuitions in the paper would generalize, a full analysis of the more general case is beyond the scope of this project.

Some interesting extensions of the model have yet to be fully explored. For 
example, although our model assumes homogeneous products, we believe that our insights are important for markets with differentiated products as well. Indeed, many of the examples that we have used to motivate the paper have featured differentiated products. The indie movie "Hustle \& Flow," for example, is unique in the sense that it is not a perfect substitute for other films being produced in Hollywood. It may be, however, an imperfect substitute for other edgy, urban, rap-oriented films. In a differentiated products world, incumbents might choose to preempt entry through product-line expansions rather than capacity expansions. Indeed, these are the types of strategies the major motion picture studios are employing.

Also, we have assumed that the two incumbents produced before the entrant did. An equally reasonable assumption would have been that all the firms produce simultaneously. In this case, our earlier discussion regarding why the duopoly output is not an equilibrium remains unchanged. If Firms A and B are ignoring the threat of entry, Firm C's best response is the same whether it moves simultaneously or subsequently. However, the entry-deterring equilibria we describe are not equilibria of the simultaneous move game. If Firms A and B both believe that Firm $\mathrm{C}$ will not enter, their best response is to produce the duopoly output.

We also could have allowed the entrant to produce first. This might be reasonable if the potential entrant were a new product innovator, but had to distribute its product through existing firms, and existing firms could choose to imitate and produce themselves. In this case, it also matters whether the incumbents buy the entrant's output before or after they produce. If they produce before the auction, it is clear again that the incumbents cannot deter entry by producing the duopoly output. If they produce after the auction, then it is clear that the entrant will produce at least the Stackelberg output since (even ignoring the externality created) the entrant can sell the role of Stackelberg leader to the two firms. So, the duopoly outcome is not an equilibrium outcome.

Finally, our ideas might apply to other vertical relationships such as licensing and franchising. In the U.S. beer industry, the incumbent beer companies control vast networks of independent beer distributors and maintain tight control through restrictive contracting practices. In the late 1990s, market leader Anheuser-Busch was investigated for alleged antitrust violations for its exclusive contracting practices, dubbed the " $100 \%$ share of mind" contracts by Chairman August Busch III. ${ }^{14}$ These contracting practices make it very difficult for entrants producing specialty beers (e.g., Sierra Nevada or Goose Island) to achieve market penetration. These difficulties have become even greater as Anheuser-Busch

\footnotetext{
${ }^{14}$ The investigation was later abandoned. "Amid Probe, Anheuser Conquers Turf," The Wall Street Journal, March 9, 1988. Note that US beer makers also distribute many foreign beers, even while introducing brands designed to compete head-to-head with these imports.
} 
has aggressively entered the specialty beer segment itself, producing "craft style" alternatives to the independent brews. Our paper may, in part, explain AnheuserBusch's product-line decisions. ${ }^{15}$

\section{Appendix}

\section{Proof of Lemma 3}

As a follower, Firm C produces $R\left(x_{A}+x_{B}, k\right)$. As a Stackelberg leader, Firm A produces

$$
\arg \max _{x_{A}} p\left(x_{A}+x_{B}+R\left(x_{A}+x_{B}, k\right)\right)-k x_{A} .
$$

Similarly, Firm B produces

$$
\arg \max _{x_{B}} p\left(x_{A}+x_{B}+R\left(x_{A}+x_{B}, k\right)\right)-k x_{B} .
$$

For linear demand, Firm i's first order condition, $i \in\{A, B\}$, is

$$
\frac{1-2 x_{i}-x_{-i}+k}{2}-k=0 .
$$

So, $x_{A}=x_{B}=(1-k) / 3$, and $x_{C}=R(2(1-k) / 3, k)=(1-k) / 6$. The industry output is $x_{A}+x_{B}+x_{C}=5(1-k) / 6$, and the market price is $p=(1+k) / 6$.

\section{Proof of Lemma 6}

Without loss of generality, suppose $x_{A} \geq x_{B}$. Firm A's valuation for entrant's output, $x_{C}$, is

$$
\begin{aligned}
\Pi_{A}\left(z_{A}\left(x_{A}+x_{C}, x_{B}\right), z_{B}\left(x_{A}+x_{C}, x_{B}\right)\right) & \\
& -\Pi_{A}\left(z_{A}\left(x_{A}, x_{B}+x_{C}\right), z_{B}\left(x_{A}, x_{B}+x_{C}\right)\right),
\end{aligned}
$$

the total revenue earned if it acquires the entrant's output, less the total revenue earned if its rival acquires the entrant's output. Similarly, Firm B's willingness to pay is

$$
\begin{aligned}
\Pi_{B}\left(z_{A}\left(x_{A}, x_{B}+x_{C}\right), z_{B}\left(x_{A}, x_{B}+x_{C}\right)\right) & \\
& -\Pi_{B}\left(z_{A}\left(x_{A}+x_{C}, x_{B}\right), z_{B}\left(x_{A}+x_{C}, x_{B}\right)\right) .
\end{aligned}
$$

\footnotetext{
${ }^{15}$ Our analysis applies in that Anheuser-Busch's relationships with its distributors are analogous to vertical integration, and product proliferation is analogous to capacity expansion.
} 
The B.E. Journal of Economic Analysis \& Policy, Vol. 7 [2007], Iss. 1 (Advances), Art. 19

So, Firm A will acquire the entrant's output as long as the total industry revenues are weakly higher when Firm A acquires $x_{C}$ than when Firm B acquires $x_{C}$ :

$$
\begin{aligned}
\Pi_{A}\left(z _ { A } \left(x_{A}+x_{C},\right.\right. & \left.\left.x_{B}\right), z_{B}\left(x_{A}+x_{C}, x_{B}\right)\right) \\
& +\Pi_{B}\left(z_{A}\left(x_{A}+x_{C}, x_{B}\right), z_{B}\left(x_{A}+x_{C}, x_{B}\right)\right) \\
& \geq \Pi_{A}\left(z_{A}\left(x_{A}, x_{B}+x_{C}\right), z_{B}\left(x_{A}, x_{B}+x_{C}\right)\right) \\
& +\Pi_{B}\left(z_{A}\left(x_{A}, x_{B}+x_{C}\right), z_{B}\left(x_{A}, x_{B}+x_{C}\right)\right)
\end{aligned}
$$

We can rewrite this expression as:

$$
\begin{aligned}
\int_{0}^{x_{C}}\left[\frac{\partial \Pi_{A}\left(z_{A}\left(x_{A}+s, x_{B}\right), z_{B}\left(x_{A}+s, x_{B}\right)\right)}{\partial x_{A}}\right. \\
\left.+\frac{\partial \Pi_{B}\left(z_{A}\left(x_{A}+s, x_{B}\right), z_{B}\left(x_{A}+s, x_{B}\right)\right)}{\partial x_{A}}\right] d s \\
\geq \int_{0}^{x_{C}}\left[\frac{\partial \Pi_{A}\left(z_{A}\left(x_{A}, x_{B}+s\right), z_{B}\left(x_{A}, x_{B}+s\right)\right)}{\partial x_{B}}\right. \\
\left.+\frac{\partial \Pi_{B}\left(z_{A}\left(x_{A}, x_{B}+s\right), z_{B}\left(x_{A}, x_{B}+s\right)\right)}{\partial x_{B}}\right] d s
\end{aligned}
$$

and a sufficient condition for this to be true is that:

$$
\begin{aligned}
\frac{\partial \Pi_{A}\left(z_{A}\left(x_{A}+s, x_{B}\right), z_{B}\left(x_{A}+s, x_{B}\right)\right)}{\partial x_{A}} & \\
& +\frac{\partial \Pi_{B}\left(z_{A}\left(x_{A}+s, x_{B}\right), z_{B}\left(x_{A}+s, x_{B}\right)\right)}{\partial x_{A}} \\
& \geq \frac{\partial \Pi_{A}\left(z_{A}\left(x_{A}, x_{B}+s\right), z_{B}\left(x_{A}, x_{B}+s\right)\right)}{\partial x_{B}} \\
& +\frac{\partial \Pi_{B}\left(z_{A}\left(x_{A}, x_{B}+s\right), z_{B}\left(x_{A}, x_{B}+s\right)\right)}{\partial x_{B}}
\end{aligned}
$$

for all $s$.

Since $x+R(x, 0)$ is increasing in $\mathrm{x}$, it follows that $x_{A}+R\left(x_{A}, 0\right) \geq x_{B}+R\left(x_{B}, 0\right)$ and $R\left(x_{B}, 0\right)-x_{A} \leq R\left(x_{A}, 0\right)-x_{B}$. We show that (3) holds for all $s$ by considering the following three cases separately: 1) $R\left(x_{B}, 0\right)-x_{A} \leq R\left(x_{A}, 0\right)-x_{B}<s$; 2) $s<R\left(x_{B}, 0\right)-x_{A} \leq R\left(x_{A}, 0\right)-x_{B}$; and 3) $R\left(x_{B}, 0\right)-x_{A} \leq s \leq R\left(x_{A}, 0\right)-x_{B}$.

Case 1. Suppose that $R\left(x_{B}, 0\right)-x_{A} \leq R\left(x_{A}, 0\right)-x_{B}<s$. Then $\partial z_{A} / \partial x_{A}=$ 
Dana and Spier: Entry Deterrence in a Duopoly Market

$$
\begin{aligned}
\partial z_{B} / \partial x_{B}=0 \text { so } & \\
\frac{\partial \Pi_{A}\left(z_{A}\left(x_{A}+s, x_{B}\right), z_{B}\left(x_{A}+s, x_{B}\right)\right)}{\partial x_{A}} & +\frac{\partial \Pi_{B}\left(z_{A}\left(x_{A}+s, x_{B}\right), z_{B}\left(x_{A}+s, x_{B}\right)\right)}{\partial x_{A}}=0
\end{aligned}
$$

and

$$
\begin{aligned}
\frac{\partial \Pi_{A}\left(z_{A}\left(x_{A}, x_{B}+s\right), z_{B}\left(x_{A}, x_{B}+s\right)\right)}{\partial x_{B}} & \\
+ & \frac{\partial \Pi_{B}\left(z_{A}\left(x_{A}, x_{B}+s\right), z_{B}\left(x_{A}, x_{B}+s\right)\right)}{\partial x_{B}}=0 .
\end{aligned}
$$

Hence, both sides of (3) are zero, and the inequality holds.

Case 2. Next, suppose that $s<R\left(x_{B}, 0\right)-x_{A} \leq R\left(x_{A}, 0\right)-x_{B}$. Then

$$
\begin{aligned}
& \frac{\partial \Pi_{A}\left(z_{A}\left(x_{A}+s, x_{B}\right), z_{B}\left(x_{A}+s, x_{B}\right)\right)}{\partial x_{A}} \\
&+\frac{\partial \Pi_{B}\left(z_{A}\left(x_{A}+s, x_{B}\right), z_{B}\left(x_{A}+s, x_{B}\right)\right)}{\partial x_{A}}=\left(x_{A}+x_{B}+s\right) p\left(x_{A}+x_{B}+s\right)
\end{aligned}
$$

and

$$
\begin{aligned}
& \frac{\partial \Pi_{A}\left(z_{A}\left(x_{A}, x_{B}+s\right), z_{B}\left(x_{A}, x_{B}+s\right)\right)}{\partial x_{B}} \\
&+\frac{\partial \prod_{B}\left(z_{A}\left(x_{A}, x_{B}+s\right), z_{B}\left(x_{A}, x_{B}+s\right)\right)}{\partial x_{B}}=\left(x_{A}+x_{B}+s\right) p\left(x_{A}+x_{B}+s\right)
\end{aligned}
$$

so, both sides of (3) are equal.

Case 3. Finally, suppose $R\left(x_{B}, 0\right)-x_{A} \leq s \leq R\left(x_{A}, 0\right)-x_{B}$. Then $z_{B}\left(x_{A}+s, x_{B}\right)$ $=x_{B}$ and $z_{A}\left(x_{A}+s, x_{B}\right)=R\left(x_{B}, 0\right)$, so the left-hand side of (3) is zero: Firm A would distribute $s$, but Firm B, on the other hand would not. Also, $z_{B}\left(x_{A}, x_{B}+s\right)=$ $x_{B}+s$ and $z_{A}\left(x_{A}, x_{B}+s\right)=R\left(x_{B}+s, 0\right)$, so, the right-hand side of (3) is:

$$
\begin{aligned}
\frac{d \Pi_{A}\left(R\left(x_{B}+s, 0\right), x_{B}+s\right)}{d x_{B}}+\frac{d \Pi_{B}\left(R\left(x_{B}+s, 0\right), x_{B}+s\right)}{d x_{B}} & \\
= & \frac{d\left(R\left(x_{B}+s, 0\right)+x_{B}+s\right) p\left(R\left(x_{B}+s, 0\right)+x_{B}+s\right)}{d x_{B}}<0
\end{aligned}
$$

This must be negative since $R\left(x_{B}+s, 0\right)+x_{B}+s>R(0,0)$ (because $x+R(x, 0)$ is increasing in $x$ ) and $x p(x)$ is maximized at $R(0,0)$, so (3) holds. 
The B.E. Journal of Economic Analysis \& Policy, Vol. 7 [2007], Iss. 1 (Advances), Art. 19

Lemma 8 We assume $x_{A} \geq x_{B}$ and let the reader infer analogous results for the case when $x_{B}>x_{A}$. Recall that Firm C's profits are equal to the difference between Firm B's profits if it acquires the output, and Firm B's profits if Firm A acquires the output, less Firm C's costs.

First, consider $\left(x_{A}, x_{B}\right)$ such that $x_{A}<R\left(x_{B}, 0\right)$ and $x_{B}<R\left(x_{A}, 0\right)$. Firm C's profits are:

1) $\left(x_{B}+x_{C}\right) p\left(x_{A}+x_{B}+x_{C}\right)-x_{B} p\left(x_{A}+x_{B}+x_{C}\right)-x_{C} k$, which is equivalent to $x_{C} p\left(x_{A}+x_{B}+x_{C}\right)-x_{C} k$, when it produces $x_{C} \leq R\left(x_{B}, 0\right)-x_{A}$ ("interval $A$ 1 ”);

2) $\left(x_{B}+x_{C}\right) p\left(x_{A}+x_{B}+x_{C}\right)-x_{B} p\left(x_{B}+R\left(x_{B}, 0\right)\right)-x_{C} k$ when its production is $R\left(x_{B}, 0\right)-x_{A}<x_{C}<R\left(x_{A}, 0\right)-x_{B}$ ("interval $A-2$ ");

3) $R\left(x_{A}, 0\right) p\left(x_{A}+R\left(x_{A}, 0\right)\right)-x_{B} p\left(x_{B}+R\left(x_{B}, 0\right)\right)-x_{C} k$ when it produces $x_{C}>$ $R\left(x_{A}, 0\right)-x_{B}$ ("interval $A-3$ ").

Next, consider $\left(x_{A}, x_{B}\right)$ such that $x_{A} \geq R\left(x_{B}, 0\right)$ and $x_{B}<x_{0}^{c}$. Firm C's profits are:

1) $\left(x_{B}+x_{C}\right) p\left(R\left(x_{B}+x_{C}\right)+x_{B}+x_{C}\right)-x_{B} p\left(R\left(x_{B}, 0\right)+x_{B}\right)-x_{C} k$ when it produces $x_{C} \leq x_{0}^{c}-x_{B}$ ("interval $D_{A}-1$ ”);

2) $x_{0}^{c} p\left(2 x_{0}^{c}\right)-x_{B} p\left(R\left(x_{B}, 0\right)+x_{B}\right)-x_{C} k$ if $x_{C}>x_{0}^{c}-x_{B}$ ("interval $D_{A}-2$ ").

Finally, consider $\left(x_{A}, x_{B}\right)$ such that $x_{A}>x_{0}^{c}$ and $x_{B}>x_{0}^{c}$. Firm C's profits are:

1) $x_{0}^{c} p\left(x_{0}^{c}+x_{0}^{c}\right)-x_{0}^{c} p\left(x_{0}^{c}+x_{0}^{c}\right)-x_{C} k=-x_{C} k<0$ for all $x_{C}$.

Remarks A through C: Necessary and Sufficient Conditions for Entry:

A) When $x_{A}<R\left(x_{B}, 0\right)$ and $x_{B}<R\left(x_{A}, 0\right)$, Firm C's profit is strictly increasing in $x_{C}$ when evaluated at $x_{C}=0$, so Firm $\mathrm{C}$ will enter if and only if $p\left(x_{A}+x_{B}\right)>k$.

B) When $x_{A} \geq R\left(x_{B}, 0\right)$ Firm $\mathrm{C}$ will enter if and only if $x_{B}<x_{k, 0}^{s}$.

Proof: First, note that the derivative of Firm C's profit when evaluated at $x_{C}=0$,

$$
x_{B} p^{\prime}\left(R\left(x_{B}, 0\right)+x_{B}\right)\left(\frac{\partial R\left(x_{B}, 0\right)}{\partial x}+1\right)+p\left(R\left(x_{B}, 0\right)+x_{B}\right)-k
$$

is positive if and only if $x_{B}<x_{k, 0}^{s}$ since $x_{k, 0}^{s}$ maximizes $x_{B} p\left(R\left(x_{B}, 0\right)+x_{B}\right)-k x_{B}$. So entry will occur if $x_{A} \geq R\left(x_{B}, 0\right)$ and $x_{B}<x_{k, 0}^{s}$. Next, note that when $x_{A} \geq$ $R\left(x_{B}, 0\right)$ and $x_{B}>x_{k, 0}^{s}$ Firm C's profits are strictly decreasing in $x_{C}$, so entry will not occur.

C) When $x_{A}>x_{0}^{c}$ and $x_{B}>x_{0}^{c}$ Firm C's profits are strictly negative for all $x_{C}>0$, so Firm $\mathrm{C}$ will not enter.

Remarks 1 through 7: Firm C's Optimal Production when $x_{A}<R\left(x_{B}, 0\right)$ and $x_{B}<R\left(x_{A}, 0\right)$

1) If $x_{A}=x_{B}$ then $R\left(x_{A}, 0\right)-x_{B}=R\left(x_{B}, 0\right)-x_{A}$ interval A-2 vanishes. 
Dana and Spier: Entry Deterrence in a Duopoly Market

2) In Interval $\mathrm{A}-2$, where $R\left(x_{B}, 0\right)-x_{A}<x_{C}<R\left(x_{A}, 0\right)-x_{B}$,

$$
\begin{aligned}
& \left(x_{B}+x_{C}\right) p\left(x_{A}+x_{B}+x_{C}\right)-x_{B} p\left(x_{B}+R\left(x_{B}, 0\right)\right)-x_{C} k \\
& =x_{C} p\left(x_{A}+x_{B}+x_{C}\right)+x_{B}\left(p\left(x_{A}+x_{B}+x_{C}\right)\right. \\
& \left.-p\left(x_{B}+R\left(x_{B}, 0\right)\right)\right)-x_{C} k \\
& \leq x_{C} p\left(x_{A}+x_{B}+x_{C}\right)-x_{C} k .
\end{aligned}
$$

3) Firm C's profit function is continuous in $x_{C}$.

4) Firm $\mathrm{C}$ will never produce $x_{C}>\max \left\{R\left(x_{A}, 0\right)-x_{B}, R\left(x_{B}, 0\right)-x_{A}\right\}$. Its profit at $x_{C}=\max \left\{R\left(x_{A}, 0\right)-x_{B}, R\left(x_{B}, 0\right)-x_{A}\right\}$ is strictly higher.

5) If $R\left(x_{A}+x_{B}, k\right) \leq R\left(x_{B}, 0\right)-x_{A}$ then Firm C's optimal production is $x_{C}^{*}=$ $R\left(x_{A}+x_{B}, k\right)$.

Proof: By Remark 4, $x_{C}^{*}$ is in A-1 or A-2. By Remark 2, the maximal profit in A-2 is less $x_{C} p\left(x_{A}+x_{B}+x_{C}\right)-x_{C} k$. But since $R\left(x_{A}+x_{B}, k\right) \leq R\left(x_{B}, 0\right)-x_{A}$, the maximal profit Interval A-1 is larger than the maximal profit in interval A-2.

6) If $R\left(x_{A}+x_{B}, k\right) \geq R\left(x_{B}, 0\right)-x_{A}$, then Firm C's optimal production satisfies $x_{C}^{*} \geq R\left(x_{B}, 0\right)-x_{A}$. More precisely, Firm C's optimal production is the larger of $x_{C}=R\left(x_{A}, k\right)-x_{B}$ and $x_{C}=R\left(x_{B}, 0\right)-x_{A}$.

Proof: First, we find the unconstrained optimal production when Firm C's profits function is $\left(x_{B}+x_{C}\right) p\left(x_{A}+x_{B}+x_{C}\right)-x_{B} p\left(x_{B}+R\left(x_{B}, 0\right)\right)-x_{C} k$ (Interval A-2). Using a change of variables, $x_{B C}=x_{B}+x_{C}$, it is easy to see that the solution is $x_{B C}=R\left(x_{A}, k\right)$, so its profit is maximized at $x_{C}=R\left(x_{A}, k\right)-x_{B}$. However, if the constraint, $R\left(x_{B}, 0\right)-x_{A}<x_{C}<R\left(x_{A}, 0\right)-x_{B}$, is binding, i.e., $R\left(x_{A}, k\right)-x_{B} \geq$ $R\left(x_{B}, 0\right)-x_{A}$, then Firm C's profits are maximized at $x_{C}=R\left(x_{B}, 0\right)-x_{A}$.

7) From Remarks 4 and 6, it follows that when $x_{A}=x_{B}$, then $x_{C}^{*} \in\left\{R\left(x_{A}+x_{B}, k\right), R\left(x_{A}\right)-x_{B}\right\}$.

\section{Proof of Proposition 1}

Proof of Existence: Consider a deviation by Firm C. By Lemma 8, Remark 7, since $x_{A}=x_{B}=(1-k) / 3, R\left(x_{B}, 0\right)-x_{A}=R\left(x_{A}, 0\right)-x_{B}$ and Firm $C$ will produce $R\left(x_{A}+x_{B}, k\right)$ if $R\left(x_{A}+x_{B}, k\right) \leq R\left(x_{B}, 0\right)-x_{A}$ and $R\left(x_{B}, 0\right)-x_{A}$ otherwise. So, Firm C's optimal production is

$$
x_{C}^{*}= \begin{cases}R\left(x_{A}+x_{B}, k\right)=(1-k) / 6 & \text { if } k \geq \frac{1}{4} \\ R\left(x_{B}, 0\right)-x_{A}=k / 2 & \text { if } k<\frac{1}{4}\end{cases}
$$

In particular, when $k>1 / 4$, Firm $\mathrm{C}$ has no profitable deviation.

Now, consider Firm A's production (or equivalently Firm B):

Claim: Given $x_{B}=(1-k) / 3$, Firm A's optimal production is either $r\left(x_{B}, k\right)=$ $(1-k) / 3$ or $R\left(x_{B}, 0\right)$. 
Proof: Suppose instead that $x_{A}^{*}<(1-k) / 3$. Firm C will produce $x_{C}=$ $R\left(x_{A}^{*}+x_{B}, k\right)$ because $R\left(x_{A}^{*}+x_{B}, k\right)<R\left(x_{A}^{*}, 0\right)-x_{B}$. Furthermore, linear demand together with $R\left(x_{A}+x_{B}, k\right)<R\left(x_{A}, 0\right)-x_{B}$ at $x_{A}=x_{B}=(1-k) / 3$ imply that $R\left(x_{A}+x_{B}, k\right)<R\left(x_{A}, 0\right)-x_{B}$ for all $x_{A}<(1-k) / 3$. So, Firm A's profit function is $x_{A} p\left(x_{A}+x_{B}+R\left(x_{A}+x_{B}, k\right)\right)-k x_{A}$, but this implies that Firm A's profits are strictly increasing in $x_{A}$ for all $x_{A}<(1-k) / 3$, which is a contradiction. Suppose that $x_{A}^{*}>(1-k) / 3$ and $R\left(x_{A}^{*}+x_{B}, k\right)>R\left(x_{B}, 0\right)-x_{A}^{*}$. Suppose further that $x_{A}^{*}>R\left(x_{B}, 0\right)>x_{0}^{c}$. Then, by Lemma 8, Firm C's profit is independent of $x_{A}$. If $x_{C} \leq x_{0}^{c}-x_{B}$, then Firm C's profit is

$$
\left(x_{B}+x_{C}\right) p\left(R\left(x_{B}+x_{C}, 0\right)+x_{B}+x_{C}\right)-x_{B} p\left(R\left(x_{B}, 0\right)+x_{B}\right),
$$

and if $x_{C}>x_{0}^{c}-x_{B}$, then Firm C's profit is

$$
x_{0}^{c} p\left(R\left(x_{0}^{c}, 0\right)+x_{0}^{c}\right)-x_{B} p\left(R\left(x_{B}, 0\right)+x_{B}\right) .
$$

Since this is what Firm A will pay for Firm C's output, Firm A earns strictly greater profit (because its costs are lower) when $x_{A}^{*}=R\left(x_{B}, 0\right)$. This is a contradiction.

Suppose, as before, that $x_{A}^{*}>(1-k) / 3$ and $R\left(x_{A}^{*}+x_{B}, k\right)>R\left(x_{B}, 0\right)-x_{A}^{*}$, but now suppose that $x_{A}^{*}<R\left(x_{B}, 0\right)$. By Lemma 6 , since $x_{A}^{*}>x_{B}$, Firm A will buy Firm C's output for Firm B's valuation. Since Firm B values Firm C's output at

$$
\left(x_{B}+x_{C}\right) p\left(R\left(x_{B}, 0\right)+x_{B}\right)-x_{B} p\left(R\left(x_{B}, 0\right)+x_{B}\right)=x_{C} p\left(R\left(x_{B}, 0\right)+x_{B}\right)
$$

when $x_{C}=R\left(x_{B}, 0\right)-x_{A}^{*}$ and $p\left(R\left(x_{B}, 0\right)+x_{B}\right)>k$, it is clear that Firm B's values Firm C's optimal output strictly greater than $k x_{C}$. So, Firm A's profit, if it produces $x_{A}^{*}<R\left(x_{B}, 0\right)$, is strictly less than

$$
R\left(x_{B}, 0\right) p\left(x_{B}+R\left(x_{B}, 0\right)\right)-\left(x_{A}+x_{C}\right) k .
$$

However, if Firm A produces $x_{A}^{*}=R\left(x_{B}, 0\right)$, then by Lemma 8, Remark 6,

$$
x_{C}^{*}=\max \left\{R\left(x_{B}, 0\right)-x_{A}, R\left(x_{A}, k\right)-x_{B}\right\},
$$

but since $R\left(x_{B}, 0\right)-x_{A}^{*}=0$ and

$$
\begin{gathered}
R\left(x_{A}^{*}, k\right)-x_{B}=\frac{1-x_{A}^{*}-k}{2}-\frac{1}{3}(1-k) \\
=\frac{1-R\left(x_{B}, 0\right)-k}{2}-\frac{1}{3}(1-k) \\
=\frac{1-\frac{1}{3}-k}{2}-\frac{1}{3}(1-k)=-\frac{k}{6}
\end{gathered}
$$


it follows that $x_{C}^{*}=0$, so if Firm A produce $x_{A}^{*}=R\left(x_{B}, 0\right)$ its profits are

$$
R\left(x_{B}, 0\right) p\left(x_{B}+R\left(x_{B}, 0\right)\right)-R\left(x_{B}, 0\right) k \text {. }
$$

Firm A's profits are strictly higher if it produces $x_{A}^{*}=R\left(x_{B}, 0\right)$. We conclude that Firm A's optimal production is either $r\left(x_{B}, k\right)=(1-k) / 3$ or $R\left(x_{B}, 0\right)$. So, we only need to consider a deviation to $R\left(x_{B}, 0\right)$ to determine whether or not $(1-k) / 3$ is Firm A's optimal strategy. Firm A's equilibrium profits are

$$
\frac{1}{3}(1-k)\left(1-\frac{5}{6}(1-k)-k\right)=\frac{1}{18}(1-k)^{2}=\frac{1}{18}-\frac{1}{9} k+\frac{1}{18} k^{2},
$$

and, since $x_{C}^{*}=R\left(x_{B}, 0\right)-x_{A}=0$, Firm A's profits at $R\left(x_{B}, 0\right)$ are

$$
\begin{aligned}
\frac{1}{3}(1+k)\left(1-\frac{1}{3}(1-k)-\frac{1}{3}(1+k)-k\right) & \\
= & \frac{1}{3}(1+k)\left(\frac{1}{3}-k\right)=\frac{1}{9}-\frac{2}{9} k-\frac{1}{3} k^{2}
\end{aligned}
$$

So Firm A will want to deviate to $R\left(x_{B}, 0\right)$ if and only if

$$
\frac{1}{9}-\frac{2}{9} k-\frac{1}{3} k^{2}>\frac{1}{18}-\frac{1}{9} k+\frac{1}{18} k^{2}
$$

or $2-4 k-6 k^{2}>1-2 k+k^{2} ; 1-2 k-7 k^{2}>0 ; k<.261204$.

\section{Proof of Uniqueness:}

Finally, we show that no other entry-accommodating equilibria exists. Suppose $\left\{x_{A}, x_{B}, x_{C}\right\}$ is an entry-accommodating equilibrium, so $x_{C}>0$.

We first claim that in any entry-accommodating equilibrium both $x_{A}<R\left(x_{B}, 0\right)$ and $x_{B}<R\left(x_{A}, 0\right)$. Suppose instead that an entry-accommodating equilibrium exists in which $x_{A} \geq R\left(x_{B}, 0\right)$ (or, by analogy, that $x_{B} \geq R\left(x_{A}, 0\right)$ ). Then, by Lemma 8 , Firm $\mathrm{C}$ will enter only if $x_{B}<x_{k, 0}^{s}$. But if $x_{B}<x_{k, 0}^{s}$, Firm B could increase its profits by producing more.

We next claim that in any entry-accommodating equilibrium

$$
x_{C}=R\left(x_{A}+x_{B}, k\right) \leq \min \left\{R\left(x_{A}, 0\right)-x_{B}, R\left(x_{B}, 0\right)-x_{A}\right\} .
$$

Suppose instead that $x_{C} \geq R\left(x_{B}, 0\right)-x_{A}$ and $x_{A} \geq x_{B}$ (or by analogy $x_{C} \geq R\left(x_{A}, 0\right)-$ $x_{B}$ and $x_{B} \geq x_{A}$ ). Since Firm A will buy Firm C's output, the equilibrium of the distribution game will be $R\left(x_{B}, 0\right)$ and $x_{B}$. If $x_{B}<x_{k, 0}^{s}$, Firm B could increase its profits by producing $x_{k, 0}^{s}$, so $x_{B} \geq x_{k, 0}^{s}$. However, this implies that if Firm A deviated to $x_{A}=R\left(x_{B}, 0\right)$, entry would be deterred, and Firm A would 
earn strictly higher profits. Since Firm A's production costs are $\left(R\left(x_{B}, 0\right)-x_{A}\right) k$ higher, but it saves at least as much as it would have paid Firm $\mathrm{C}$ if Firm $\mathrm{C}$ produced $x_{C}=R\left(x_{A}, 0\right)-x_{B}$, which is Firm B's valuation for $x_{C}=R\left(x_{A}, 0\right)-x_{B}$ :

$$
\begin{array}{r}
\left(x_{B}+R\left(x_{B}, 0\right)-x_{A}\right) p\left(x_{A}+x_{B}+R\left(x_{B}, 0\right)-x_{A}\right)-x_{B} p\left(R\left(x_{B}, 0\right)+x_{B}\right) \\
=\left(R\left(x_{B}, 0\right)-x_{A}\right) p\left(x_{B}+R\left(x_{B}, 0\right)\right) .
\end{array}
$$

So, in every entry-accommodating equilibria it must be that $x_{C}=R\left(x_{A}+x_{B}, k\right) \leq$ $\min \left\{R\left(x_{A}, 0\right)-x_{B}, R\left(x_{B}, 0\right)-x_{A}\right\}$

Therefore, since Firm $C$ produces $x_{C}=R\left(x_{A}+x_{B}, k\right)$, Firm A maximizes its profits by choosing $x_{A}=r\left(x_{B}\right)$, and Firm B maximizes its profits by choosing $x_{B}=r\left(x_{A}\right)$. So, the unique, entry-accommodating equilibrium is

$$
\left\{x_{A}, x_{B}, x_{C}\right\}=\left\{\frac{1-k}{3}, \frac{1-k}{3}, \frac{1-k}{6}\right\} .
$$

\section{Proof of Proposition 2}

We will demonstrate that no firm has a profitable deviation when $k \leq 1 / 6$ and at least one firm does when $k>1 / 6$.

First, consider Firm C. By Lemma 8 (Remark C), if $x_{A} \geq x_{0}^{c}$ and $x_{B} \geq x_{0}^{c}$, then Firm C's best response is $x_{C}=0$, so in particular $x_{C}=0$ is its best response to $x_{A}=x_{B}=x_{0}^{c}$.

Next, consider Firm A (and by analogy Firm B). Neither Firm A nor Firm B has an incentive to produce more than $x_{0}^{c}$. By Lemma 8 , such a deviation would have no effect on Firm $\mathrm{C}$, and by Lemma 5 it would have no effect on their revenues in the distribution game, but it would increase their costs but not their revenues. Suppose Firm A (and by analogy Firm B) could increase its profit by producing $x_{A}<x_{B}=x_{0}^{c}$. By Lemma 8 , as long as $p\left(x_{A}+x_{0}^{c}\right)>k$, which follows from $k \leq 1 / 6$, Firm $\mathrm{C}$ can profitably produce.

Claim: If $x_{A}<x_{B}=x_{0}^{c}$ and $k<1 / 3$, then Firm C's optimal production satisfies $x_{C} \geq R\left(x_{A}, 0\right)-x_{0}^{c}>0$.

Proof of Claim: By Lemma 8, Remark 5, Firm C will produce $R\left(x_{A}+x_{B}, k\right)$ if $R\left(x_{A}+x_{B}, k\right)<R\left(x_{B}, 0\right)-x_{A}$ and $x_{C} \geq R\left(x_{A}, 0\right)-x_{B}$ otherwise. So, it is sufficient to show that $R\left(x_{A}+x_{B}, k\right)>R\left(x_{B}, 0\right)-x_{A}$. Since

$$
R\left(x_{A}+x_{B}, k\right)=\arg \max _{x_{C}} x_{C} p\left(x_{A}+x_{B}+x_{C}\right)-x_{C} k
$$

it follows that when $x_{B}=x_{0}^{c}=1 / 3$ and demand is linear, then $R\left(x_{A}+x_{B}, k\right)=$ $1 / 3-x_{A} / 2-k / 2$. Also $R\left(x_{A}, 0\right)-x_{B}=1 / 2-x_{A} / 2-1 / 3=1 / 6-x_{A} / 2$. So, $R\left(x_{A}+x_{B}, k\right)>R\left(x_{B}, 0\right)-x_{A}$ when $k<1 / 3$. 
Since $x_{A}<x_{B}$, Firm B will acquire $x_{C}$. Since $x_{B}+x_{C}=x_{0}^{c}+x_{C} \geq R\left(x_{A}, 0\right)$ (by the previous claim), Firm B will distribute only $R\left(x_{A}, 0\right)$. So, when Firm A deviates to any $x_{A}<x_{0}^{c}$, Firm A's profits will be $x_{A} p\left(x_{A}+R\left(x_{A}, 0\right)\right)-k x_{A}$. The optimal deviation for Firm A solves

$$
\max _{x_{A}} x_{A} p\left(x_{A}+R\left(x_{A}, 0\right)\right)-k x_{A}
$$

subject to $x_{A}<x_{0}^{c}$. For linear demand, the unconstrained solution to this problem is $x_{A}=x_{k, 0}^{s}=1 / 2-k$. So, for $k \leq 1 / 6, x_{A} \geq 1 / 3$ no profitable deviation exists, but for $k>1 / 6$, Firm A can increase its profits by producing $x_{A}=1 / 2-k$.

\section{Proof of Proposition 3}

To prove that $\left\{x_{k, 0}^{s}, R\left(x_{k, 0}^{s}, 0\right), 0\right\}$ (and by analogy $\left\{R\left(x_{k, 0}^{s}, 0\right), x_{k, 0}^{s}, 0\right\}$ ) is an equilibrium if and only if $k \in(1 / 6,1 /(2 \sqrt{2})]$ we must show that no profitable deviation exists for any player when $k \in(1 / 6,1 /(2 \sqrt{2})]$ and that a profitable deviation does exist when $k \notin(1 / 6,1 /(2 \sqrt{2})]$.

Suppose $k<1 / 6$, so $x_{k, 0}^{s}>R\left(x_{k, 0}^{s}, 0\right)$. It is clear from Lemma 8 that entry is deterred. In the distribution stage, Firm B will distribute all of its production, $R\left(x_{k, 0}^{s}, 0\right)$, but Firm A will distribute only $R\left(R\left(x_{k, 0}^{s}, 0\right), 0\right)$. If Firm A deviates and produces $R\left(R\left(x_{k, 0}^{s}, 0\right), 0\right)$, entry is still deterred, and distribution remains the same, but Firm A's costs are lower. So, $\left\{x_{k, 0}^{s}, R\left(x_{k, 0}^{s}, 0\right), 0\right\}$ is not an equilibrium when $k<1 / 6$. It follows that $x_{k, 0}^{s} \leq R\left(x_{k, 0}^{s}, 0\right)$.

First, consider possible deviations from equilibrium by Firm C. By Lemma 8 , Remark C, it is clear that Firm C will not produce.

Second, consider possible deviations from equilibrium by Firm A. First, suppose Firm A deviates by producing more than $x_{k, 0}^{s}$. Then, by Lemma 8, Firm C will still produce nothing.

If $x_{A}<x_{0}^{c}$ (Firm A's deviation is not too large), then in the distribution stage Firm A will distribute $x_{A}$, and Firm B will withhold some of its output and distribute $R\left(x_{A}, 0\right)<R\left(x_{k, 0}^{s}, 0\right)$. So, the optimal deviation for Firm A maximizes $x_{A} p\left(x_{A}+R\left(x_{A}, 0\right)\right)-k x_{A}$ subject to $x_{A}<x_{0}^{c}$. But the solution to this problem is $x_{k, 0}^{s}$ if $k>1 / 6$.

If Firm A's deviation is large, so $x_{A}>x_{0}^{c}$, then both firms will distribute $x_{0}^{c}$. Firm A's profits are no more than $x_{0}^{c} p\left(x_{0}^{c}+x_{0}^{c}\right)-k x_{0}^{c}$, which is less than $x_{k, 0}^{s} p\left(x_{k, 0}^{s}+R\left(x_{k, 0}^{s}, 0\right)\right)-k x_{k, 0}^{s}$ for $k>1 / 6$. So, an increase in Firm A's production is never profitable.

Now, suppose that Firm A deviates by producing less than $x_{k, 0}^{s}$.

Claim: If $x_{A}<x_{k, 0}^{s}, x_{B}=R\left(x_{k, 0}^{s}, 0\right)$, and $k<1 / 2$ then Firm C's optimal production satisfies $x_{C} \geq R\left(x_{A}, 0\right)-x_{B}>0$. 
Proof of Claim: By Lemma 8, Remark 5, Firm C will produce $R\left(x_{A}+x_{B}, k\right)$ if $R\left(x_{A}+x_{B}, k\right)<R\left(x_{B}, 0\right)-x_{A}$, and $x_{C} \geq R\left(x_{A}, 0\right)-x_{B}$ otherwise. So, it is sufficient to show that $R\left(x_{A}+x_{B}, k\right)>R\left(x_{B}, 0\right)-x_{A}$. Recall that

$$
R\left(x_{A}+x_{B}, k\right)=\arg \max _{x_{C}} x_{C} p\left(x_{A}+x_{B}+x_{C}\right)-x_{C} k .
$$

Using linear demand, and substituting both $x_{k, 0}^{s}=1 / 2-k$ and $x_{B}=R\left(x_{k, 0}^{s}, 0\right)=$ $(1+2 k) / 4$ into the objective function, this optimization yields $R\left(x_{A}+x_{B}, k\right)=$ $3 / 8-x_{A} / 2-3 k / 4$. Also using linear demand and $x_{B}=x_{0}^{c}=1 / 3, R\left(x_{A}, 0\right)-x_{B}=$ $1 / 2-x_{A} / 2-(1+2 k) / 4=1 / 4-x_{A} / 2+k / 2$, so $R\left(x_{A}+x_{B}, k\right)>R\left(x_{B}, 0\right)-x_{A}$ when $k<1 / 2$.

Since $x_{A}<x_{B}$, Firm B will acquire $x_{C}$. Since $x_{B}+x_{C}=x_{0}^{c}+x_{C} \geq R\left(x_{A}, 0\right)$ (by the previous claim), Firm B will distribute only $R\left(x_{A}, 0\right)$. So, when Firm A deviates to any $x_{A}<x_{0}^{c}$, Firm A's profits will be $x_{A} p\left(x_{A}+R\left(x_{A}, 0\right)\right)-k x_{A}$. So, the most profitable deviation for Firm $\mathrm{A}$ is $x_{A}=\arg \max _{x_{A}} x_{A} p\left(x_{A}+R\left(x_{A}, 0\right)\right)-k x_{A}$ which is equal to $x_{k, 0}^{s}$.

So, no profitable deviation exists for Firm A.

Finally, consider possible deviations from equilibrium by Firm B. Clearly, Firm B cannot increase its profit by producing more than $R\left(x_{k, 0}^{s}, 0\right)$ : Firm $\mathrm{C}$ would still produce zero. So, Firm B would be earning the same revenue at higher cost.

Suppose Firm B produced less than $R\left(x_{k, 0}^{s}, 0\right)$.

Claim: If $x_{A}=x_{k, 0}^{s}$ then Firm C's best response to $x_{B}=1 / 4$ is $R\left(x_{B}+x_{k, 0}^{s}, k\right)$ if and only $k \geq 1 / 4$.

Proof: Given that Firm B deviates to $x_{B}=1 / 4$, so $x_{B} \geq x_{A}=x_{k, 0}^{s}=1 / 2-k$, by Lemma 8, Remark 6, Firm C's best response is $R\left(x_{A}+x_{B}, k\right)$ if $R\left(x_{A}+x_{B}, k\right)<$ $R\left(x_{A}, 0\right)-x_{B}$ and $x_{C} \geq R\left(x_{A}, 0\right)-x_{B}$ otherwise. Since Firm A produces $x_{k, 0}^{s}=$ $1 / 2-k$ and Firm B produces $1 / 4$,

$$
R\left(x_{A}+x_{B}, k\right)=\frac{1-\frac{1}{4}-\left(\frac{1}{2}-k\right)-k}{2}=\frac{1}{8},
$$

and

$$
R\left(x_{A}, 0\right)-x_{B}=\frac{1-\left(\frac{1}{2}-k\right)}{2}-\frac{1}{4}=\frac{k}{2},
$$

so then Firm C's best response is $R\left(x_{A}+x_{B}, k\right)$ if and only if $k \geq 1 / 4$.

Consider Firm B's profits when it chooses some deviation $x_{B}<R\left(x_{k, 0}^{s}, 0\right)$ to which Firm C's best response is $x_{C}=R\left(x_{A}+x_{B}, k\right)$. Firm B's profits from such a deviation are $x_{B} p\left(x_{B}+x_{k, 0}^{s}+R\left(x_{B}+x_{k, 0}^{s}, k\right)\right)$, which is clearly less than $\max _{x_{B}} x_{B} p\left(x_{B}+x_{k, 0}^{s}+R\left(x_{B}+x_{k, 0}^{s}, k\right)\right)$. For linear demand, this upper bound is

$$
\max _{x_{B}} x_{B}\left(\frac{1-x_{k, 0}^{s}-x_{B}-k}{2}\right),
$$


which is maximized at $x_{B}=1 / 4$ where Firm B's profits are

$$
x_{B} \frac{1}{2}\left(\frac{1}{2}-x_{B}\right)=\frac{1}{32} .
$$

But by the claim $x_{C}=R\left(x_{A}+x_{B}, k\right)$ is Firm C's best response to $x_{C}=1 / 4$ when $k>1 / 4$. So, Firm B's most profitable deviation is $x_{B}=1 / 4$ and its profits from that deviation are $1 / 32$. However, there are also deviations to which Firm C's optimal response satisfies $x_{C} \geq R\left(x_{k, 0}^{s}, 0\right)-x_{B}$, and we must also show that these do not earn higher profits.

Suppose Firm C's optimal response to a deviation by Firm B satisfies $x_{C} \geq$ $R\left(x_{k, 0}^{s}, 0\right)-x_{B}$. If $x_{B} \in\left[x_{k, 0}^{s}, R\left(x_{k, 0}^{s}, 0\right)\right)$ then Firm B will acquire Firm C's output in the auction (because it is larger) and then distribute $R\left(x_{k, 0}^{s}, 0\right)$ in the distribution stage. Firm B distributes the same amount as when it produces the equilibrium output, $R\left(x_{k, 0}^{s}, 0\right)$, and so earns the same revenue, but its costs are strictly higher (because it pays Firm $\mathrm{C}$ more than $k$ for that output). If $x_{B} \in\left[0, x_{k, 0}^{s}\right]$, then Firm A will withhold some output in Stage 4 and distribute $R\left(x_{B}, 0\right)$. An upper bound for Firm B's payoff from a deviation satisfying $x_{B} \in\left[0, x_{k, 0}^{s}\right]$ is the profit that solves

$$
\max _{x_{B}} x_{B} p\left(x_{B}+R\left(x_{B}, 0\right)\right)-k x_{B},
$$

subject to $x_{B} \in\left[0, x_{k, 0}^{s}\right]$. The upper bound of this expression is achieved at $x_{B}=$ $1 / 2-k$ (notice that $x_{B}=x_{k, 0}^{s}$, so the constraint is not binding). Firm B's profits from this deviation are $(1 / 2)[1 / 2-k]^{2}$. But Firm B's equilibrium profits are $(1 / 4)[1 / 2-k][1 / 2+k]$. It that Firm B will not find it profitable to deviate whenever $k>1 / 6$. Therefore, Firm B will deviate to $x_{B}=1 / 4$ if and only if $1 / 32$ is greater than its equilibrium profits, $1 / 4\left(1 / 4-k^{2}\right)$, or $k>1 /(2 \sqrt{2})$.

\section{Proof of Proposition 4}

From Lemma 8, entry is deterred only if either $x_{A} \geq R\left(x_{B}, 0\right), x_{B} \geq R\left(x_{A}, 0\right)$ or $p\left(x_{A}+x_{B}\right) \leq k$. However, when $p\left(x_{A}+x_{B}\right) \leq k$, Firms $\mathrm{A}$ and $\mathrm{B}$ cannot be producing optimally since profits are zero or negative for both firms. Also note that $x_{A}>R\left(x_{B}, 0\right)$ and $x_{B}>R\left(x_{A}, 0\right)$ are inconsistent with profit maximization since production could be reduced without changing distribution or revenues. So, in any pure strategy, entry-deterring equilibrium either $x_{A}=R\left(x_{B}, 0\right)$ or $x_{B}=$ $R\left(x_{A}, 0\right)$ must hold. So, all the candidates for an equilibrium are of the form $\{\dot{x}, R(\dot{x}, 0), 0\}$ where $\dot{x}<R(\dot{x}, 0)$ or equivalently, $\dot{x}<x_{0}^{c}$. Graphically, since $x_{A} \leq R\left(x_{B}, 0\right)$ and $x_{B} \leq R\left(x_{A}, 0\right)$, the equilibrium candidates lie on the portion of the firm's zero-cost reaction functions that are on the boundary of Region A in Figures 4, 5, and 6. 
Consider $k \leq 1 / 6$. Suppose there exists an equilibrium $\{\dot{x}, R(\dot{x}, 0), 0\}$ where $\dot{x}<x_{0}^{c}$, that is, an equilibrium different from the equilibrium in Proposition 2. Note that $x_{A} p\left(x_{A}+R\left(x_{A}, 0\right)\right)-k x_{A}$ is concave and for $k \leq 1 / 6$, we have $x_{0}^{c} \leq$ $\arg \max _{x_{A}} x_{A} p\left(x_{A}+R\left(x_{A}, 0\right)\right)-k x_{A}$ (see proof of Proposition 2). If Firm A deviates to $x_{0}^{c}$, Firm B will distribute only $R\left(x_{0}^{c}, 0\right)$ so Firm A's profits are $x_{0}^{c} p\left(x_{0}^{c}+\right.$ $\left.R\left(x_{0}^{c}, 0\right)\right)-k x_{0}^{c}$, which must be higher. So, no such equilibrium exists.

Consider $k>1 / 6$. Suppose there exists an equilibrium $\{\dot{x}, R(\dot{x}, 0), 0\}$ where $\dot{x} \neq \arg \max _{x_{A}} x_{A} p\left(x_{A}+R\left(x_{A}, 0\right)\right)-k x_{A}$, so it is different from the equilibrium in Proposition 3. If $\dot{x}<\arg \max _{x_{A}} x_{A} p\left(x_{A}+R\left(x_{A}, 0\right)\right)-k x_{A}$ Firm A can deviate to $x_{k, 0}^{s}$ and earn strictly higher profit since Firm B will distribute $R\left(x_{k, 0}^{s}, 0\right)$. If $\dot{x}>\arg \max _{x_{A}} x_{A} p\left(x_{A}+R\left(x_{A}, 0\right)\right)-k x_{A}$ then Firm A can deviate to $x_{k, 0}^{s}$, which will induce entry, and Firm B will again distribute $R\left(x_{k, 0}^{s}, 0\right)$, so Firm A is better off. So, no such equilibrium exists.

The same argument holds for an equilibrium of the form $\{R(\dot{x}, 0), \dot{x}, 0\}$. So, the only candidates for an equilibrium are $\left\{x_{k, 0}^{s}, R\left(x_{k, 0}^{s}, 0\right), 0\right\}$ and $\left\{R\left(x_{k, 0}^{s}, 0\right), x_{k, 0}^{s}, 0\right\}$, where $x_{k, 0}^{s}=\arg \max _{x_{A}} x_{A} p\left(x_{A}+R\left(x_{A}, 0\right)\right)-k x_{A}$, and we showed in Proposition 3 that these candidate equilibria exist if and only if $k \in(1 / 6,1 /(2 \sqrt{2})]$.

\section{References}

[1] Chen, Yongmin (2000) "Strategic Bidding by Potential Competitors: Will Monopoly Persist?," Journal of Industrial Economics, 48(2), 161-75.

[2] Chen, Yongmin (2001) "On Vertical Mergers and Their Competitive Effects," RAND Journal of Economics, 32(4), 667-85.

[3] Dixit, A. (1980) "The Role of Investment in Entry Deterrence," Economic Journal, 90, 95-106.

[4] Eso, Peter, Volke Nocke, and Lucy White (2006) "Competition for Scarce Resources," Northwestern University, mimeo.

[5] Gilbert, Richard J. and Xavier Vives (1986) "Entry Deterrence and the Free Rider Effect," Review of Economic Studies, 53(1), 71-83.

[6] Gilbert, Richard J. and David M. G. Newbery (1982) "Preemptive Patenting and the Persistence of Monopoly," American Economic Review, 72(3), 51426.

[7] Hart, Oliver, and Jean Tirole (1990) "Vertical Integration and Market Foreclosure," Brookings Papers on Economic Activity, 205-76. 
[8] Hoppe, Heidrun, Philippe Jehiel, and Benny Moldavanu (2006) "License Auctions and Market Structure," Journal of Economics and Management Strategy, 15(2), 371-96.

[9] Kamien, Morton, and Israel Zang (1990) "The Limits of Monopolization Through Acquisition," Quarterly Journal of Economics, 105, 465-99.

[10] Krishna, Kala (1993) "Auctions with Endogenous Valuations: The Persistence of Monopoly Revisited," American Economic Review, 84, 147-60.

[11] Lewis, Tracy (1983) "Preemption, Divestiture, and Forward Contracting in a Market Dominated by a Single Firm," American Economic Review, 73, 1092-101.

[12] Molnar, Jozsef (2000) "Preemptive Horizontal Mergers: Theory and Evidence," Northwestern University, mimeo.

[13] Ordover, Saloner, and Salop (1990) "Equilibrium Vertical Foreclosure," American Economic Review, 80, 127-42.

[14] Rasmusen, Eric (1988) "Entry for Buyout," Journal of Industrial Economics, 36(3), 281-99.

[15] Reinganum, Jennifer (1983) "Uncertain Innovation and the Persistence of Monopoly," America Economic Review, 73, 741-48.

[16] Salinger, Michael (1988) "Vertical Mergers and Market Foreclosure," Quarterly Journal of Economics; 103(2), 345-56.

[17] Salop, S.C. and Scheffman, D.T. (1987) "Cost-Raising Strategies," Journal of Industrial Economics, 36, 19-34.

[18] Spence, A.M. (1977) "Entry, Capacity, Investment, and Oligopolistic Pricing," Bell Journal of Economics, 8, 534-44.

[19] Waldman, Michael (1987) "Noncooperative Entry Deterrence, Uncertainty, and the Free Rider Problem," Review of Economic Studies, 54, 301-10. 